\title{
منهجية محمود محمد طه في كتابيه خطوة نحو الزواج في الإسلام، وتطوير شريعة الأحوال الشخصية
}

\author{
عبدالإله كنه محجوب \\ دكتوراه مقارنة الأديان \\ جامعة بحري- السودان \\ kunasugud@gmail.com
}

إسماعيل صديق عثمان إسماعيل

أستاذ مشارك- قسم مقارنة الأديان

جامعة بحري- السودان

dr.ismailsiddig@gmail.com 


\title{
منهجية محمود محمد طه في كتابيه خطوة نحو الزواج في الإسلام، وتطويرشريعة الأحوال الشخصية
}

\author{
إسماعيل صهديق عثمان إسماعيل

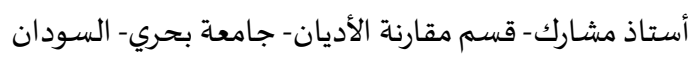 \\ dr.ismailsiddig@gmail.com \\ عبدالإله كنه محجوب \\ دكتوراه مقارنة الأديان- جامعة بحري- السودان \\ kunasugud@gmail.com
}

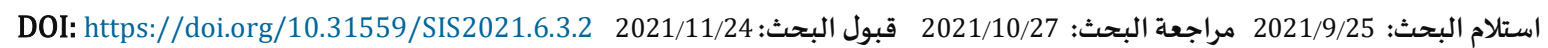

في هذا البحث الموسوم ب (منهجية محمود محمد طه في كتابيه خطوة نحو الزواج في الإسلام وتطوير شريعة الأحوال الشخصية)، نتناول أحد أهم كتب محمود بجانب كتابيه الرسالة الثانية من الإسلام ورسالة الصلاة، وهو كتاب تطوير الأحوال

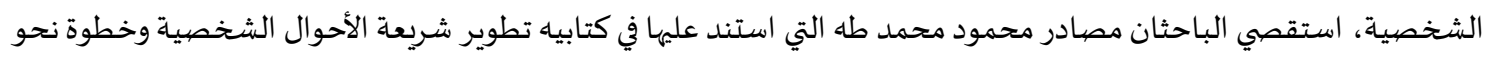

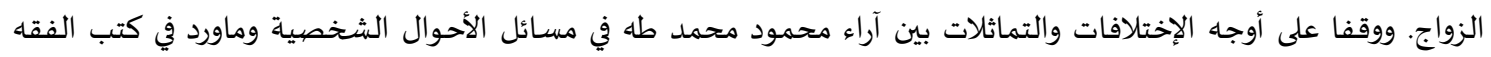

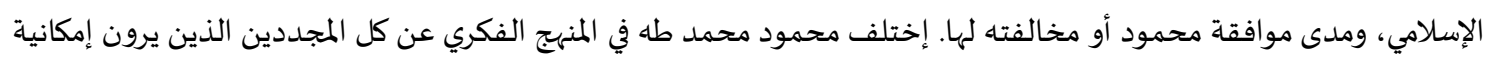
كفالة حقوق المرأة باجتهادات جديدة في الشريعة الإسلامية، بينما يرى محمود أن لا مساواة بين الرجل والمرأة في الشريعة لألان

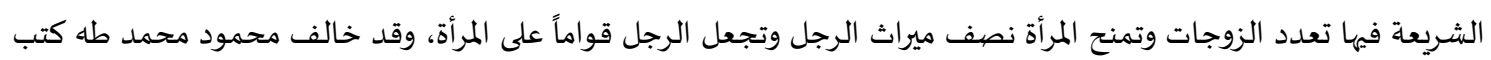

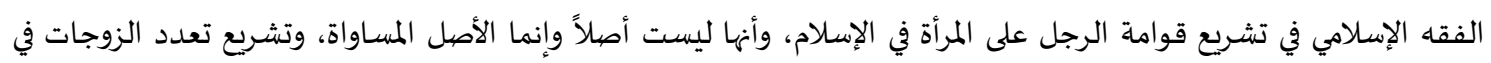

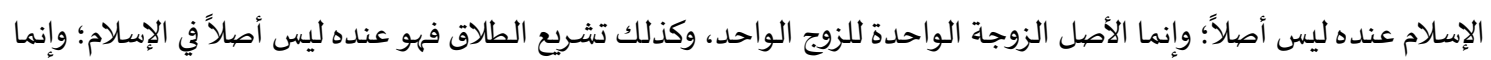

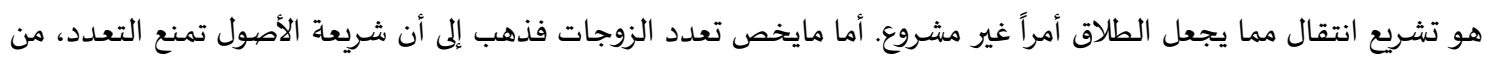

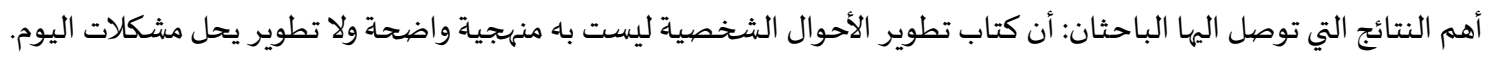

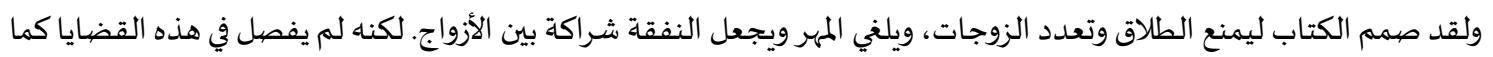
فعل الفقه الموروث، ولم يلتفت إلى المشكلات التي يمكن أن تنجم من أحكامه هذه، كما أنه لم يُعر قضايا المواريث أي إهتمام رغم المهم أنها تقع ضمن قوانين الأحوال الشخصية. وقد اتبع الباحثان المنهج الوصفي التحليلي من خلال أسلوبي الإستنباط والاستقراء وكذلك المنهج المقارن للوصول فوانين للمراميهما. الكلمات المفتاحية: محمود محمد طاء؛ وتطوير شريعة الأحوال الشخصية؛؛ حقوق المرأة.

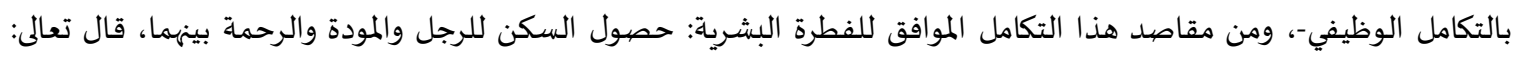




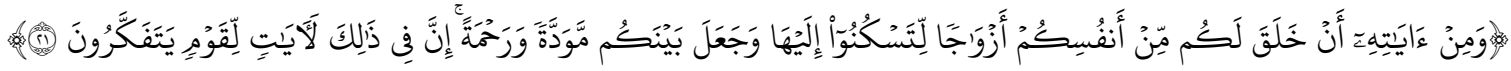

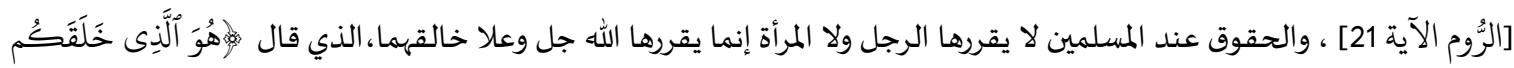

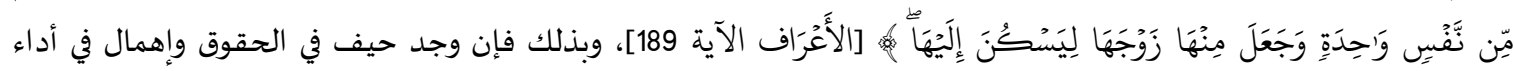

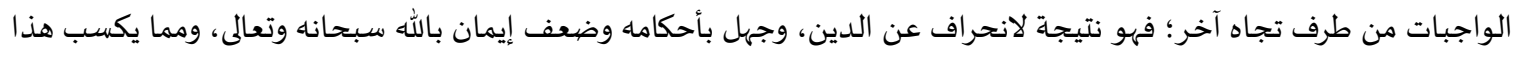

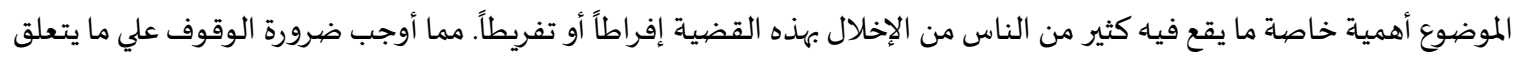

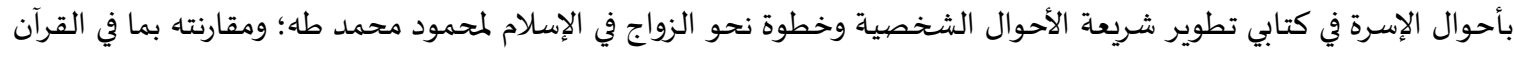

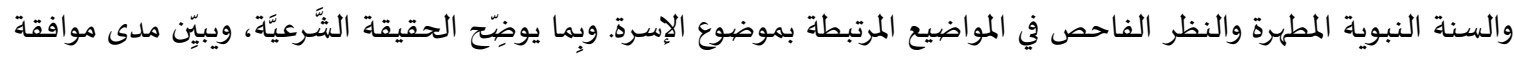

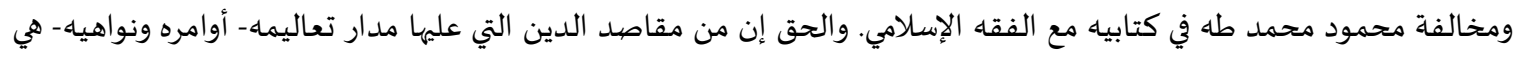

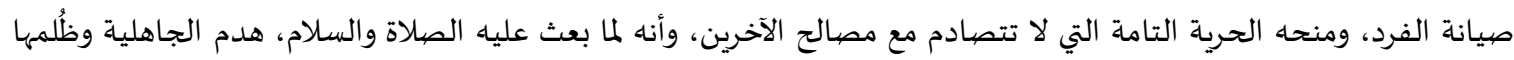

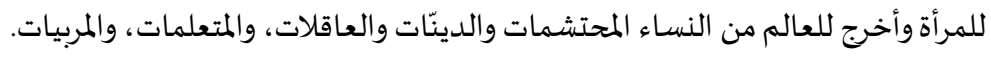

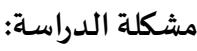

يرى الباحثان أنه لابد من معرفة بعض الأسئلة والمنطلقات التي يجب الرجوع إلها والصديدور عنها للولوج في هذا البحث وهي:

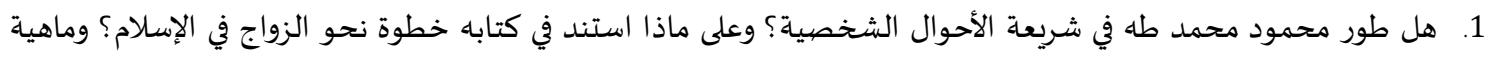

منهجيته؟ 2. ما أهمية القضايا التي تناولها محمود في كتابه شريعة الأحوال الشخصية؟ ماهو رأيه في الطلاق، وتعدد الزوجات، وماهي ضرورة تناول كتابيه ومقارنتهما بما ورد في الفقه الإسلامي؟ هذه الأسئلة وغيرها ومايمكن أن ينجم عنها من إجابات قد تكون قي شكل مقاربات أو أو استنتاجات أو حقائق ستمثل مشكلة هذا البحث. منهج الدراسة: ولتحقيق المرامي التي يسعى إليها الباحثان سيتبعان المنهج الوصفي التحليلي من خلال أسلوبي الاستنباط والاستقراء، وكذلك المنهج المقارن.

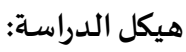
المبحث الأول: محمود محمد طه المولد والتعليم ومصهادر المعرفة.

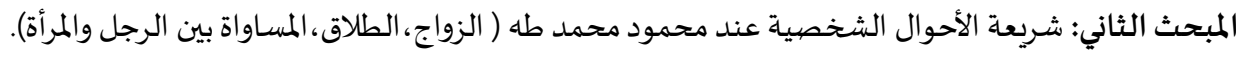

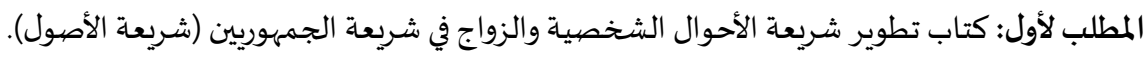
المطلب الثاني: الزواج في الحقيقة.

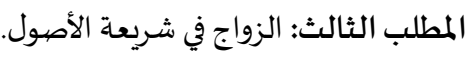

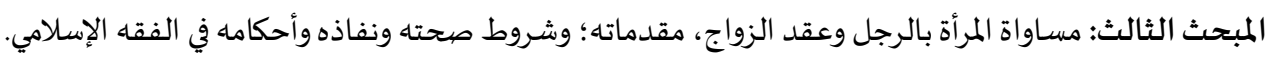
المطلب الأول: مساواة المرأة بالرجل. المطلب الثاني: مسؤولية الرجل والمرأة في بناء الأسرة.

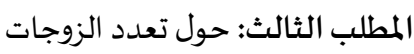

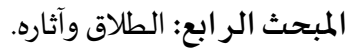
المطلب الأول: تعريف الطلاق. المطلب الثاني: مشروعية الطلاق وحكماه. المطلب الثالث: طلاق المرأة نفسها.

المبحث الخامس: نماذج من أوجاه الإختلافات والتماثلات بين آراء محمود محمد طه والمذاهب الفمقهية في مسائل الأحوال 
المبحث الأول: محمود محمد طه المولد والتعليم ومصيادر المعرفة

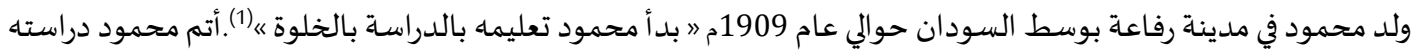

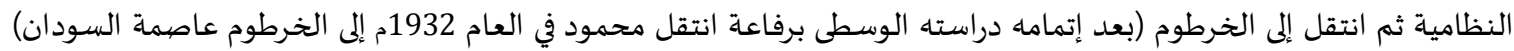

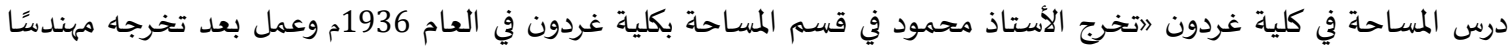

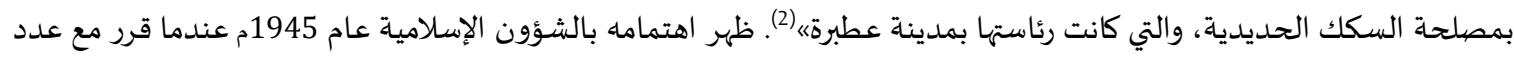
من أصحابه تأسيس الحزب الجمهوري السوداني، في 26 أكتوبر، وهو من أوائل الأحزاب السودانية التي نادت باستقالالال السودان السانيان

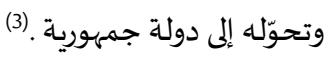

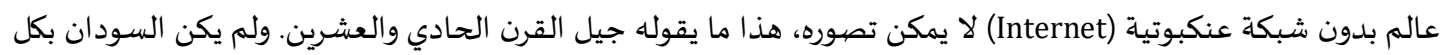

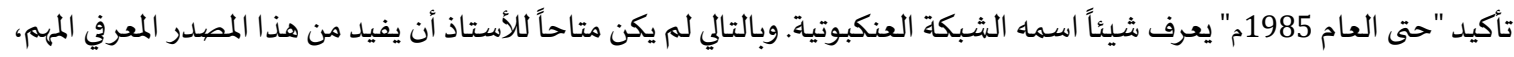

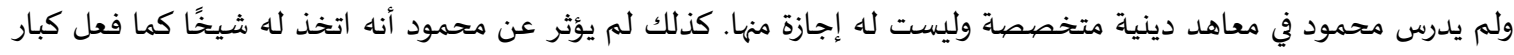

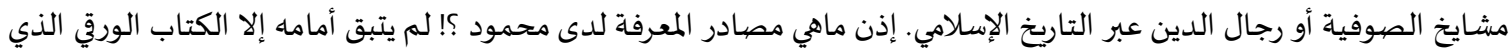

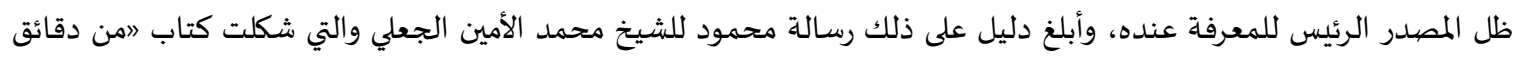

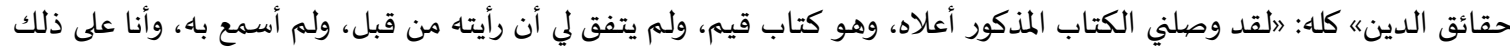

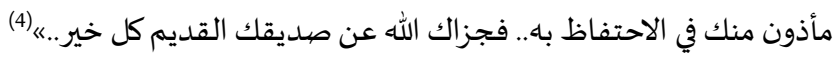

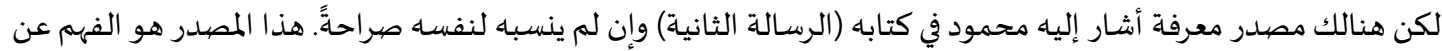

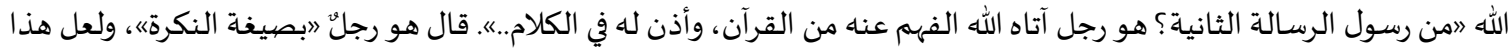
"أي الفهم عن الله" يكشف محاولة تسويغ إفراغ القرآن مما يعطيه ظاهره ومن قواعد اللغانة العربية في بعض تفسيرات الفرات محمودد، رغم

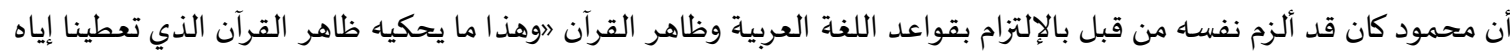

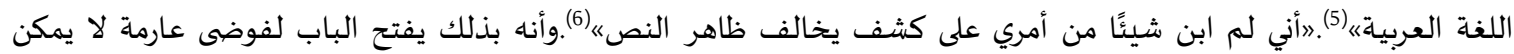

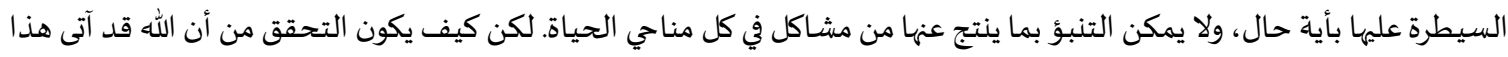

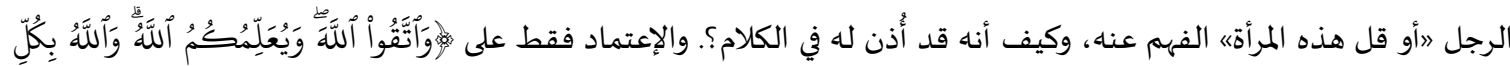

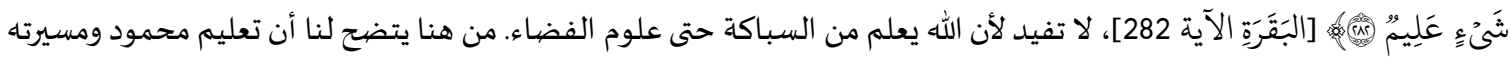

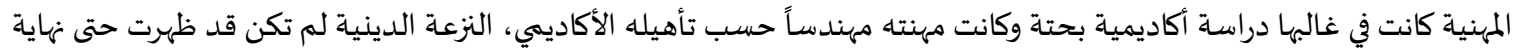

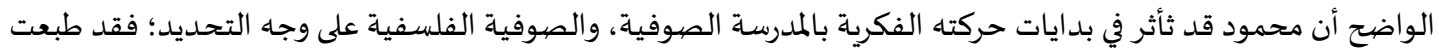

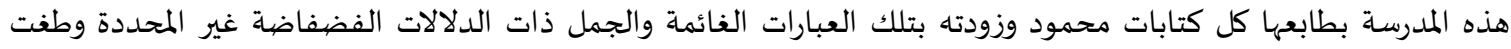

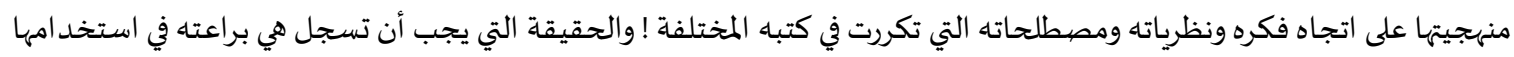

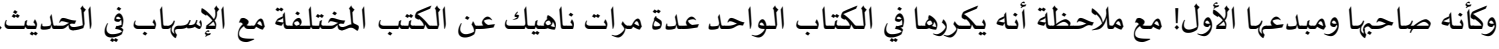

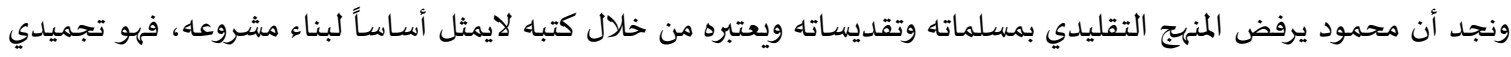

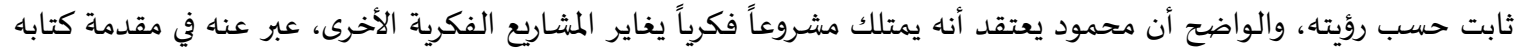

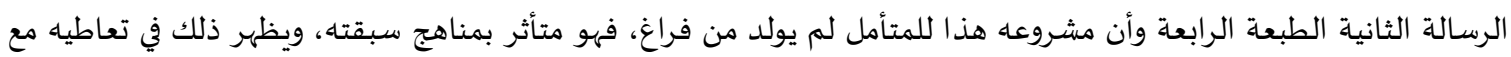

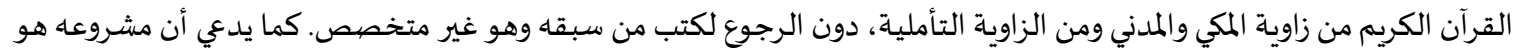

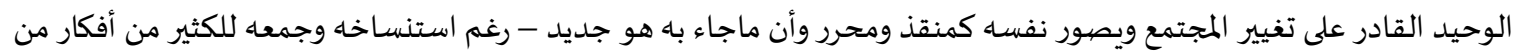

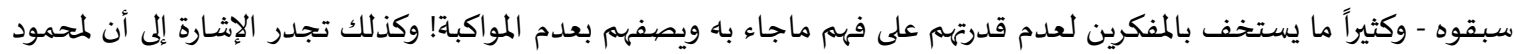
نزعة صوفية متجذرة، مع مايصاحب التصوف من شطحات فكرية يصعب فهمها! ويستعمل محمود كلمات متعارف عليها بين الفقهاء

لمحات من حياة الأستاذ محمود محمد طه. إصدارات مركز الأستاذ محمود محمد طه الثقافي ص 1.

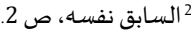
الس السابق، نفس الصفحة. " من دقائق حقائق الدين، محمود محمد طه. مايو 1981. ص ص 12.

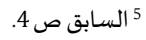

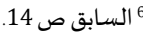


ورجال المسلمين والمثقفين والعامة، ولكنه يعطيها معناً خاصًِا. وهو مايخلق سوء التفاهم بينها وبين معارضياه. فهم يفهمون كلامه كما متعارف بينهم، بينما هو لا يعني مايعنون.

المبحث الثاني: شريعة الأحوال الشخصية عند محمود محمد طه (الزواج، الطلاق، المساواة بين الرجل والمرأة)

المطلب لأول: كتاب تطويرشريعة الأحوال الشخصية والزواج في شريعة الجمهوريين (شريعة الأصهول):

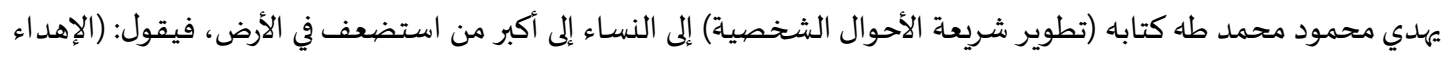

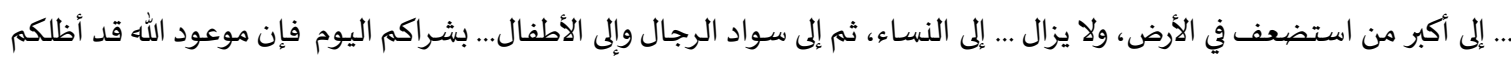

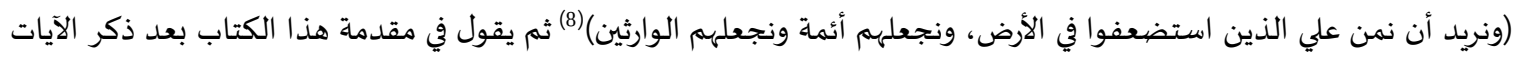

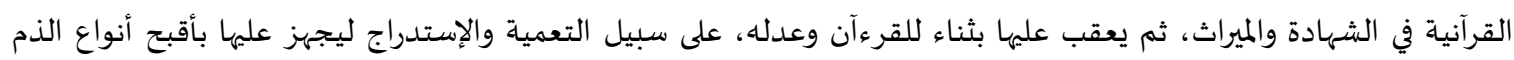

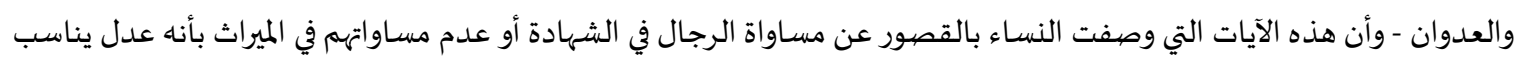

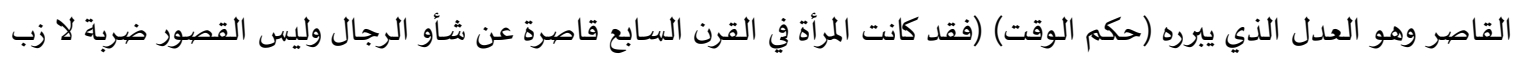

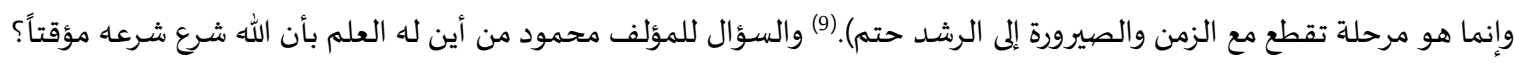

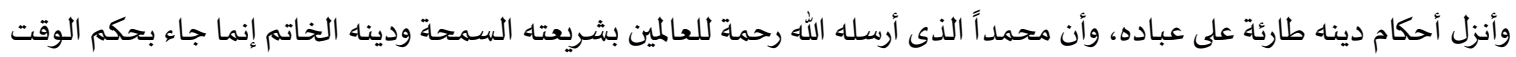

لاهل القرن السابع فقط، (10).

يعتبر كتاب تطوير شريعة الأحوال الشخصية من أهم كتب محمود؛ وقد جاء الكتاب استجابة لوعد قطعها على نفسه في خاتمة

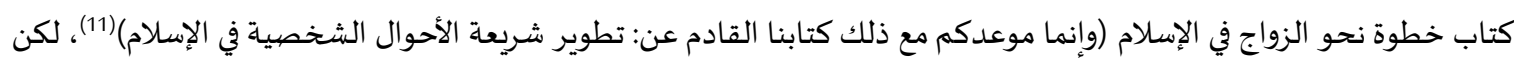

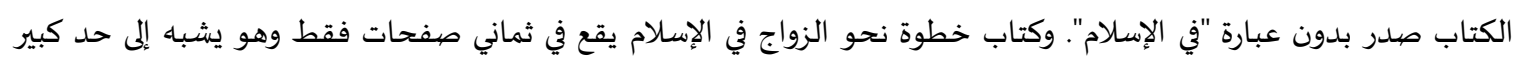

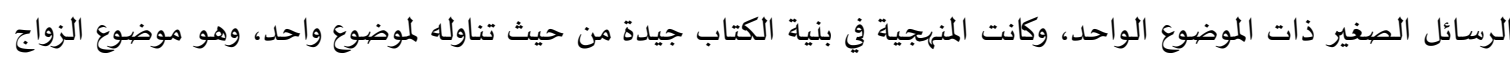

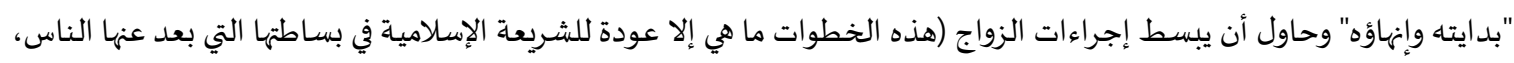

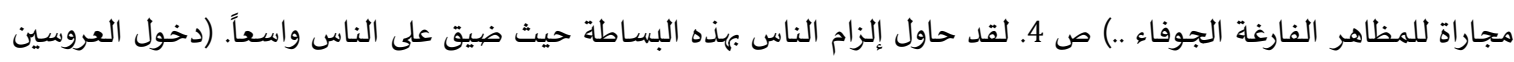

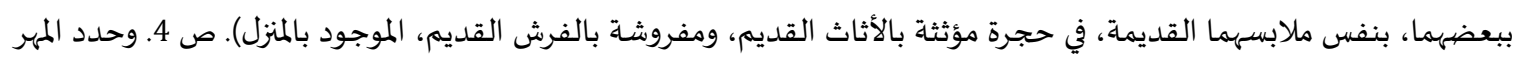

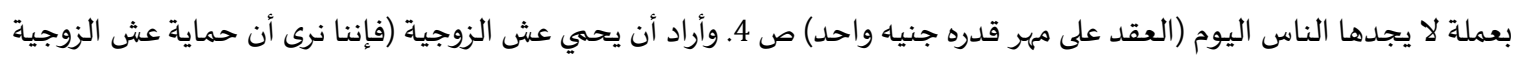

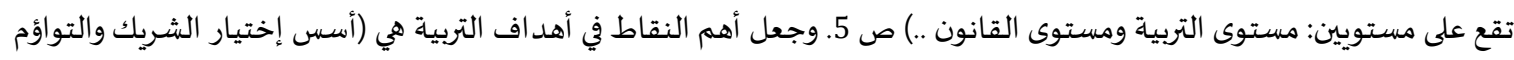

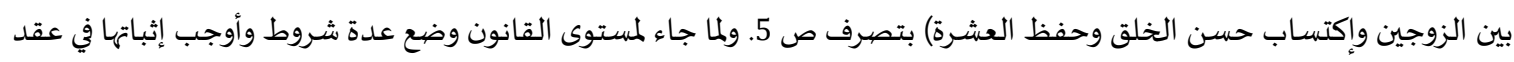

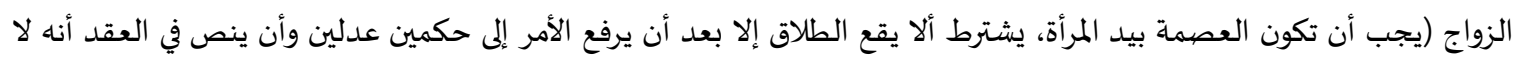

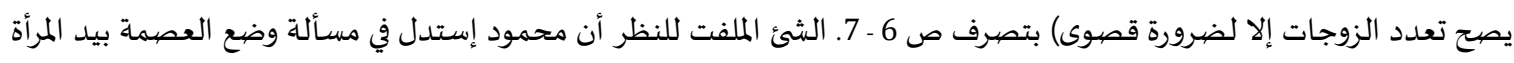

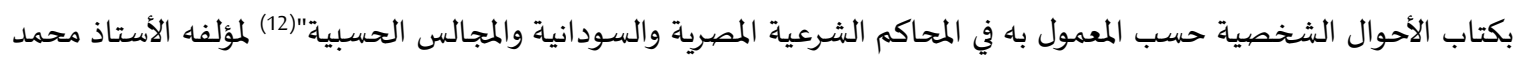

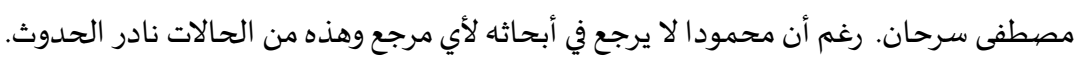

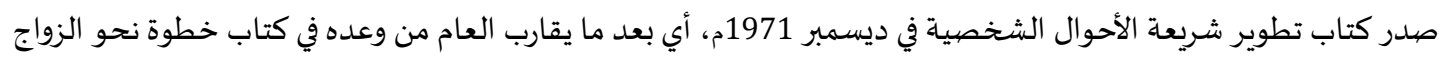

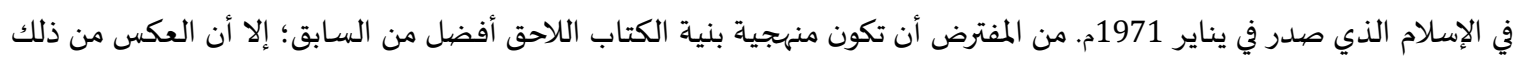

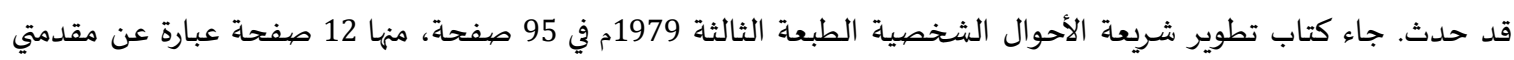

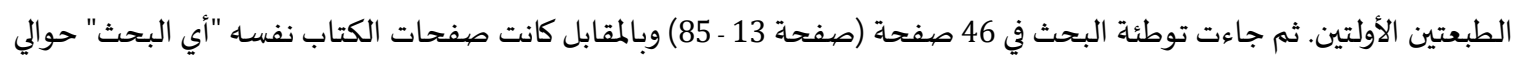

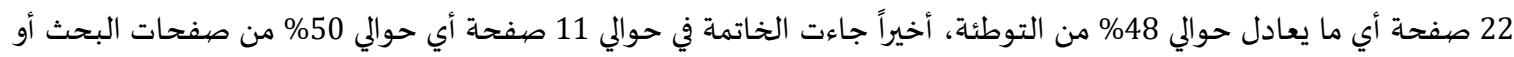

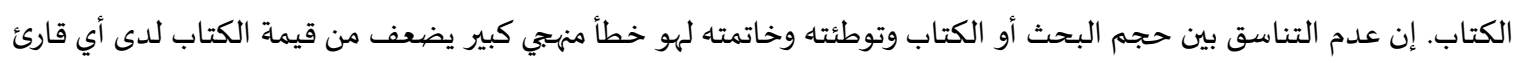

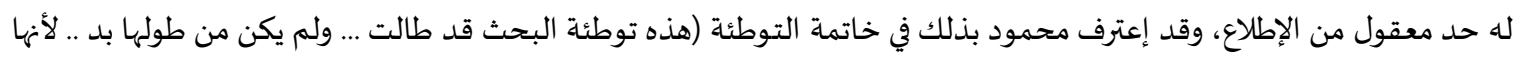

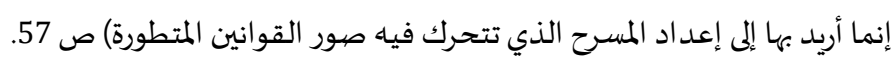

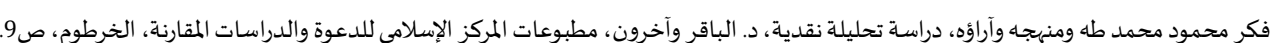

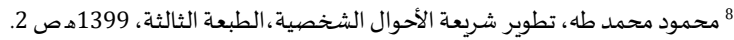

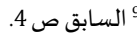
10 محمود محمد طابه، تطوير شربعة الأحوال الشخصية ، السابق،نفس الصفحة.

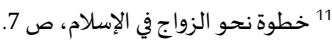

12 الأستاذ محمد مصطفى سرحان، "الأحوال الشخصية حسب المعمول به في المحاكم الشرعية المصرية والسودانية والمجالس الحسبية بتصرف ص 5. 


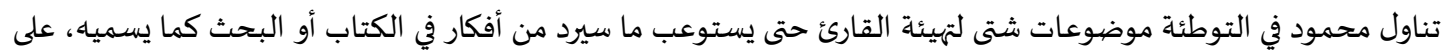

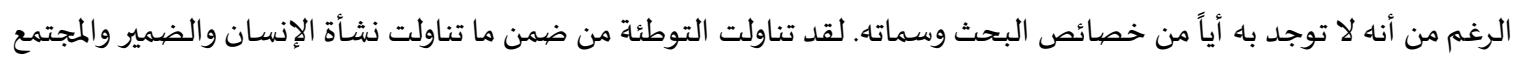

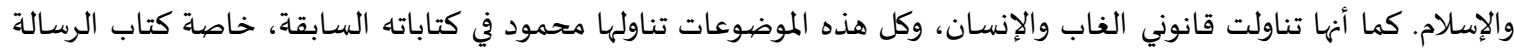

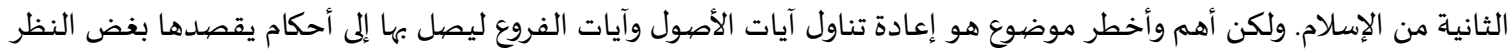

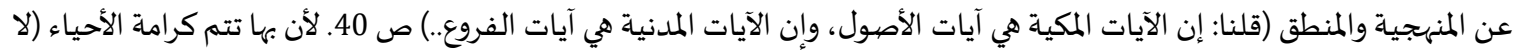

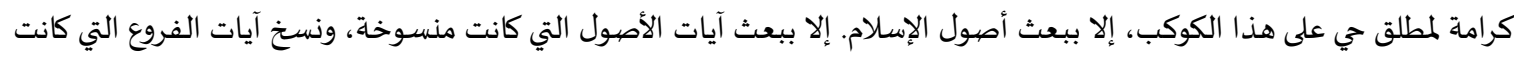

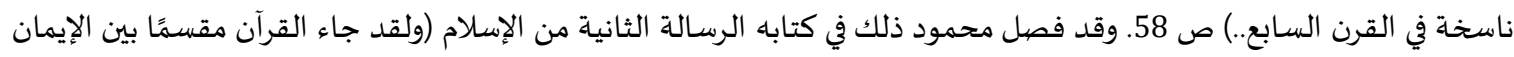

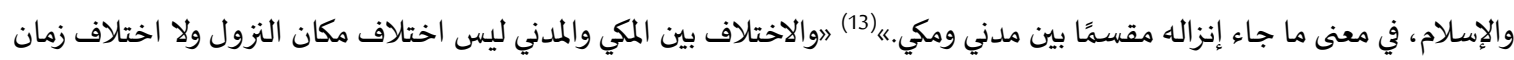

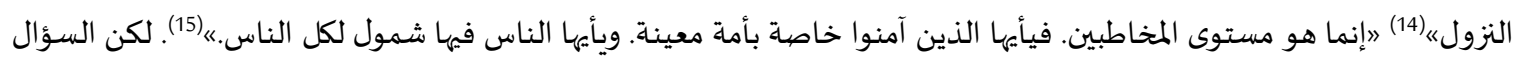

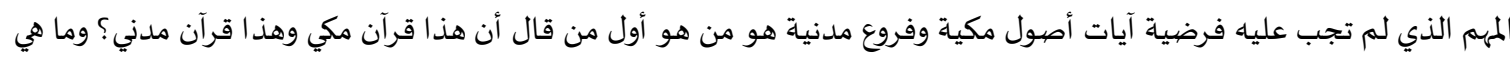

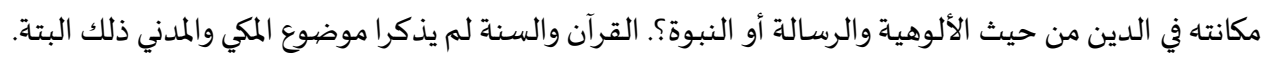

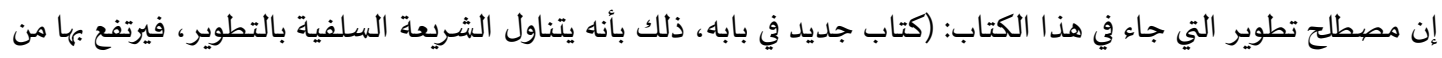

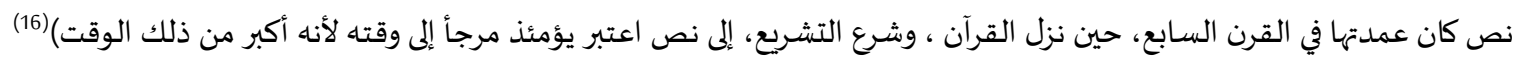

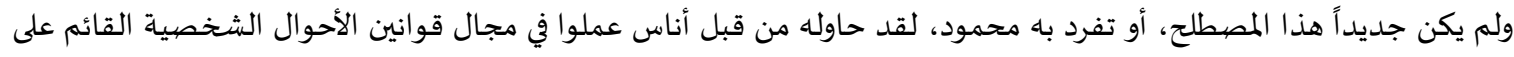

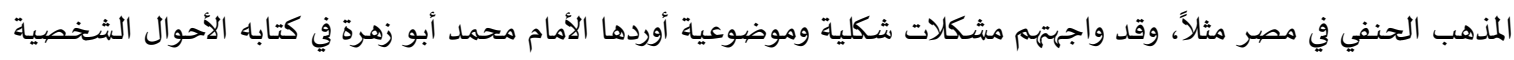

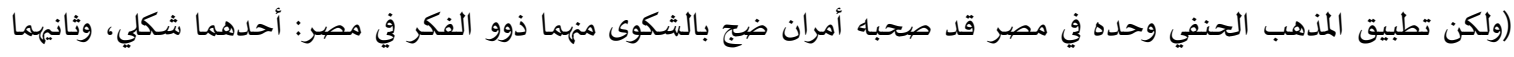

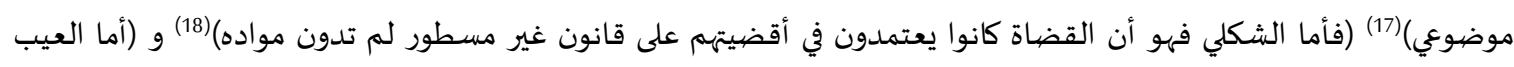

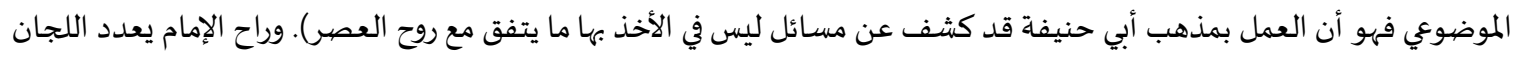

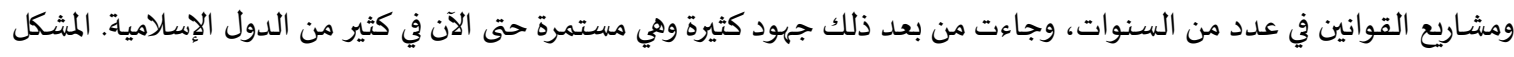

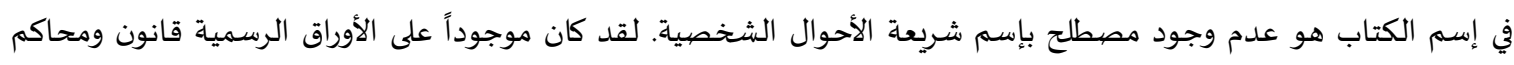

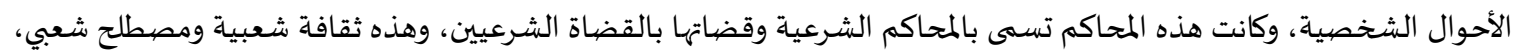

ولكن الأستاذ دمج الإسمين وخرج بهذان هذه المجاك المصطلح.

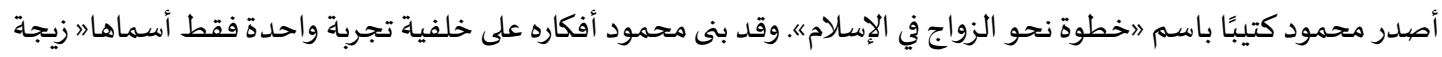

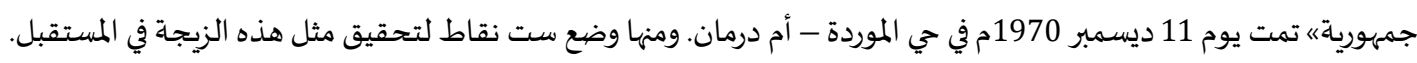

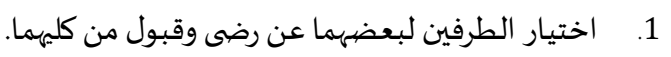

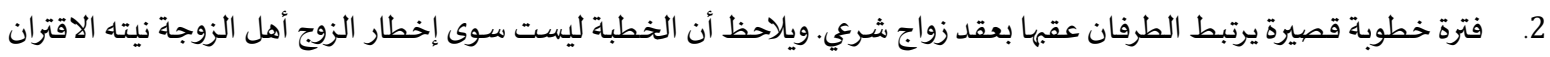

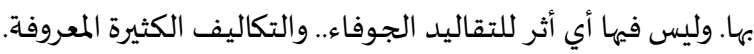

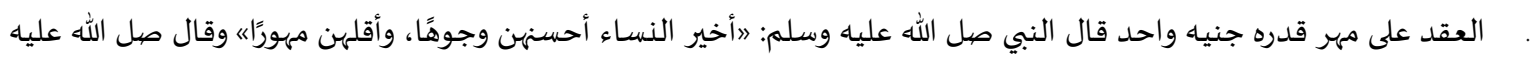

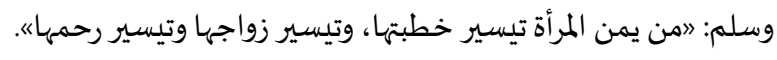

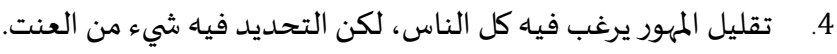
5.

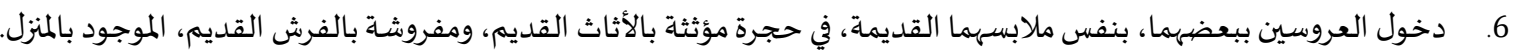

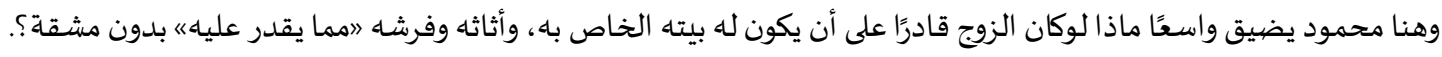

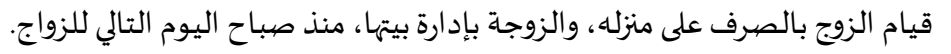

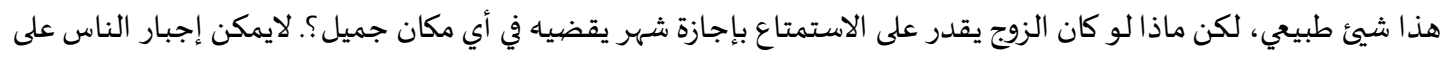

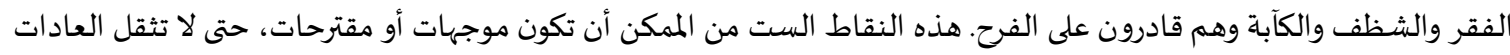

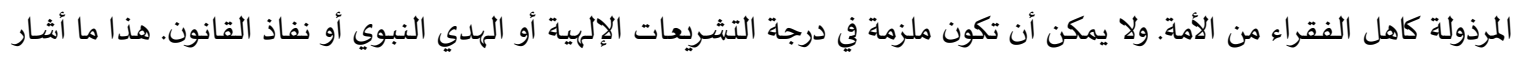

1313 الرسالة الثانية، مرجع سابق ص 109

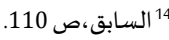
(15 السابق نفس الصفحة 14 16 تطوير شريعة الأحوال الشخصية، 15

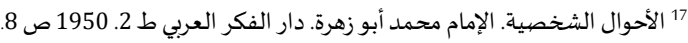
18 
إليه محمود بقوله: 》وأول ما ينبغي ملاحظته أن السعادة لا تنبني على القانون، إنما تنبني على المعرفة بطبائع الناس《)(19). ما ينبغي

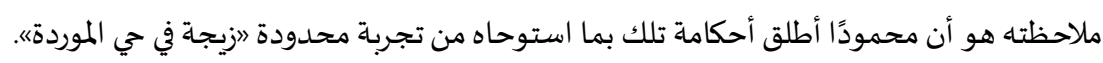

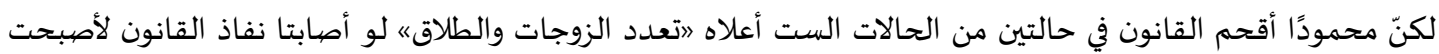

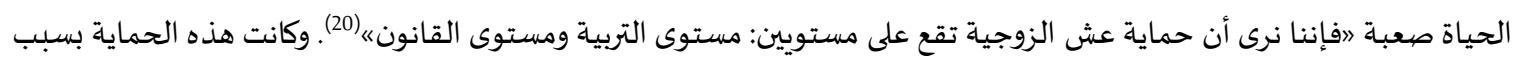

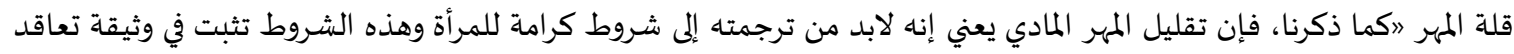

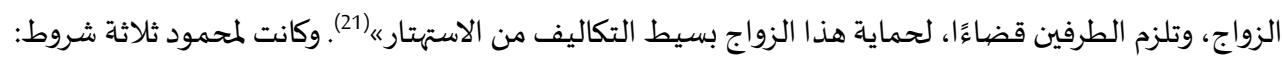

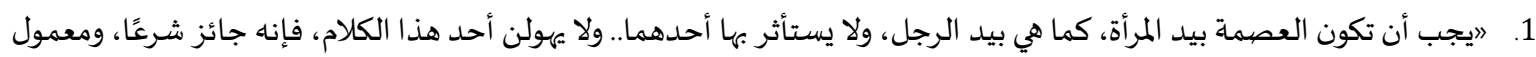

باه قضاءهاء

$$
\text { 3. } 3 .
$$

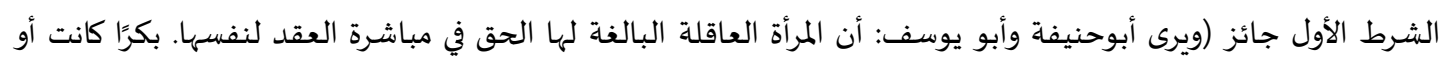

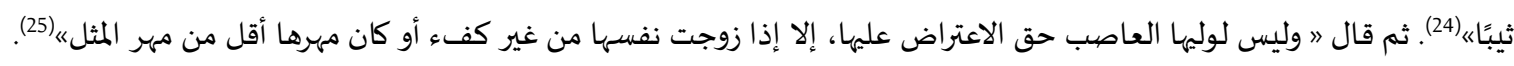

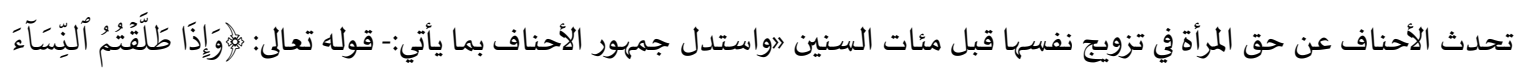

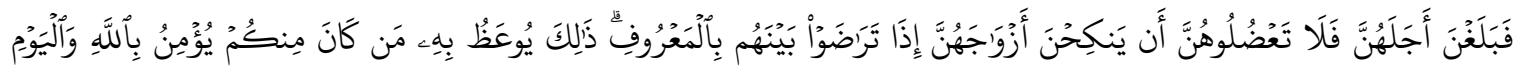

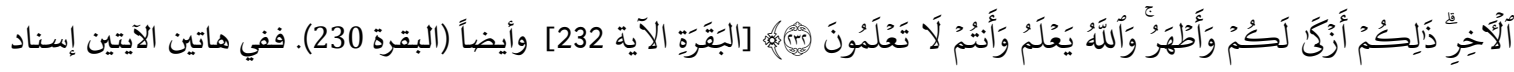

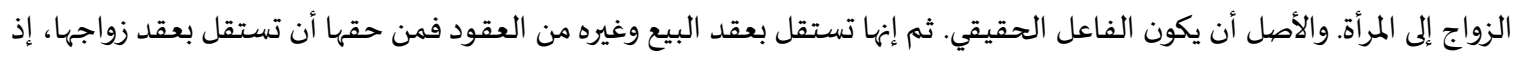

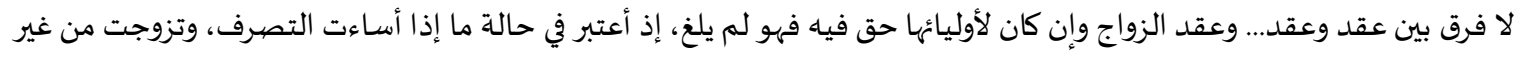

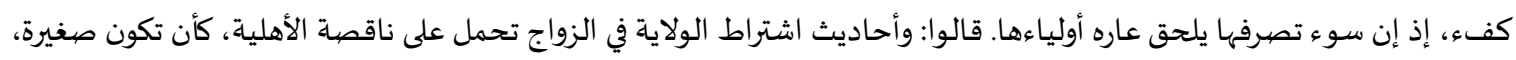

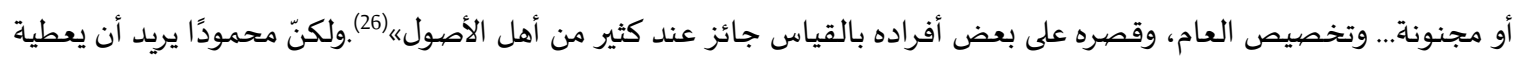

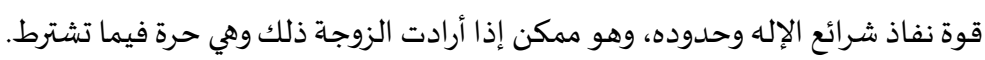

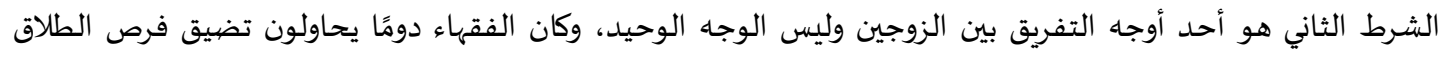

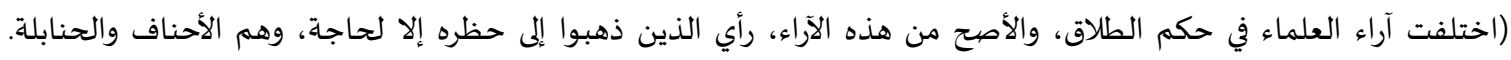

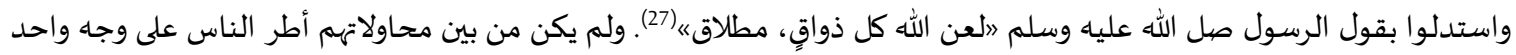

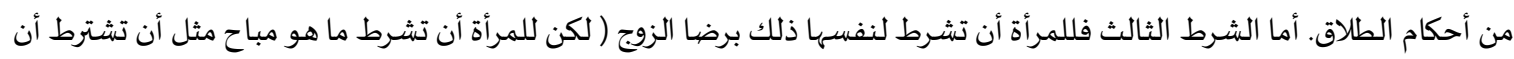

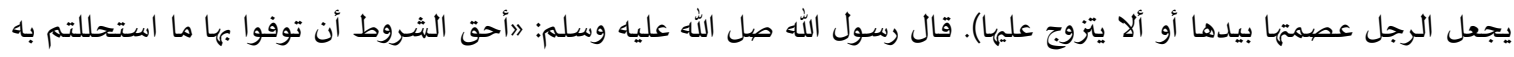
الفروجه رواه الشيخان. (28)

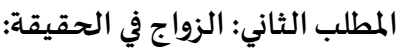

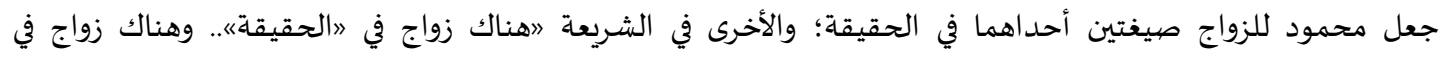

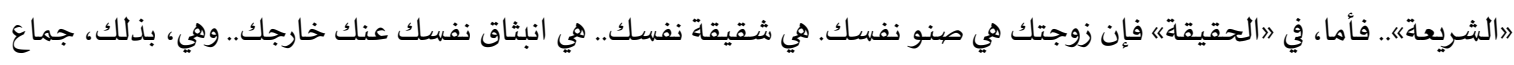

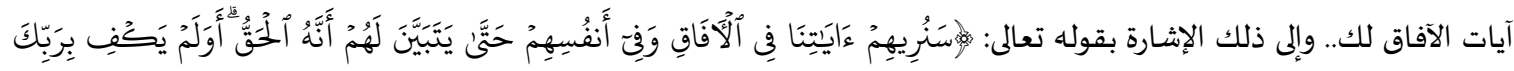

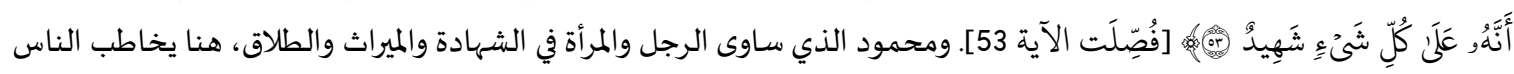

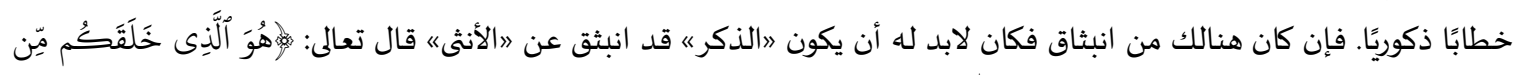

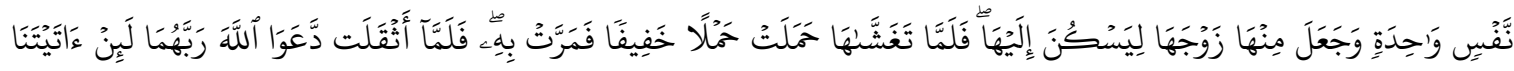

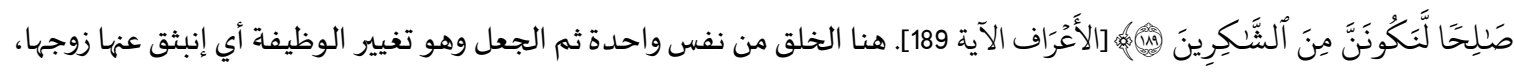

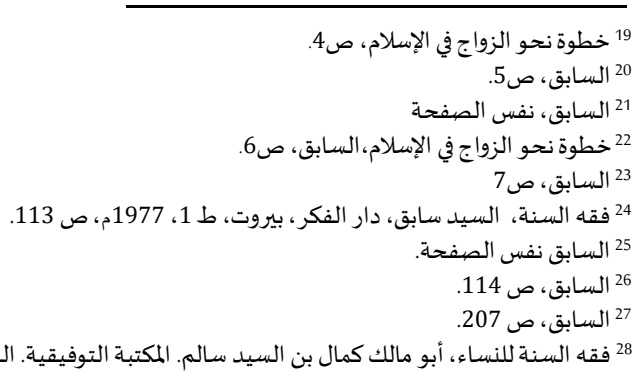

22 فقه السنة للنساء، أبو مالك كمال بن السيد سالم. المكتبة التوفيقية. القاهرة. 2000م. ص 437. 


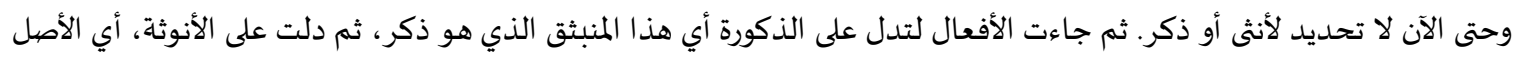

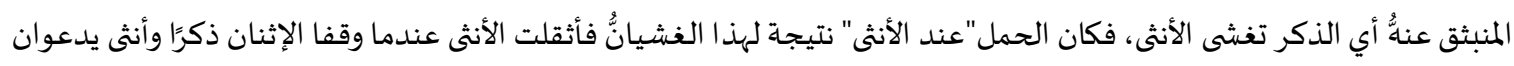

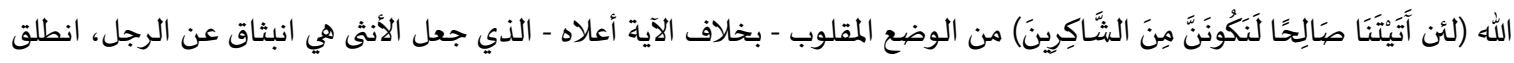

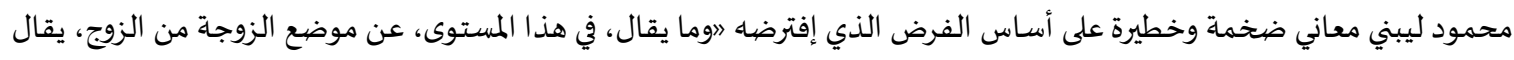

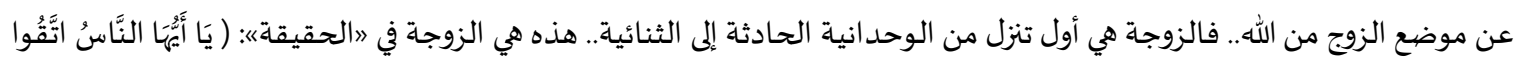

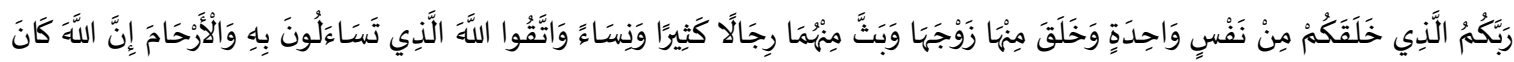

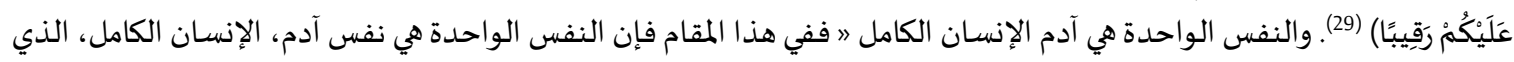

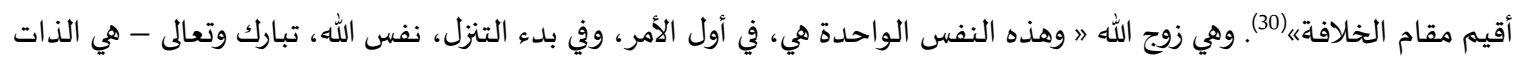

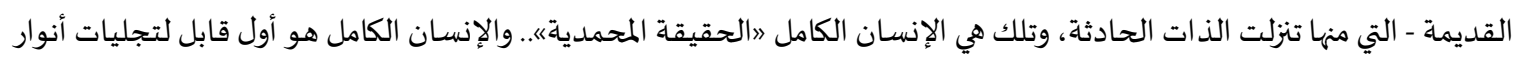

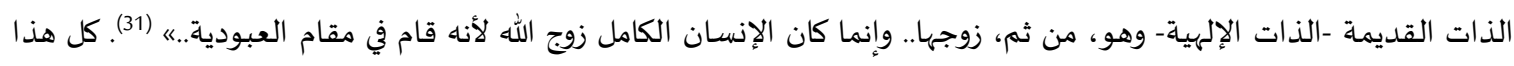

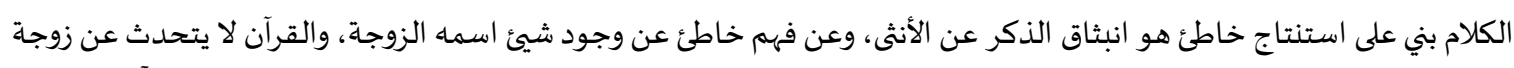

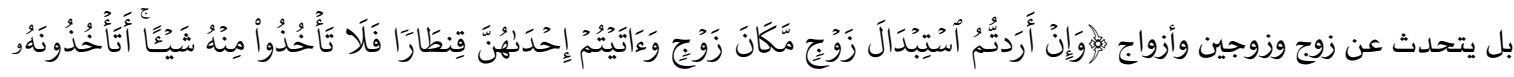

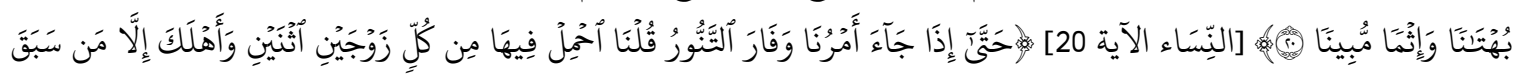

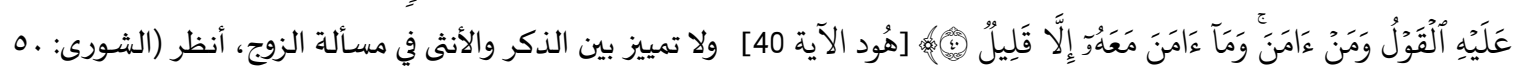

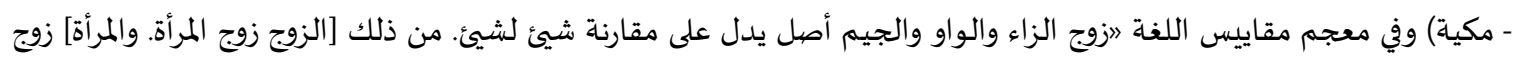

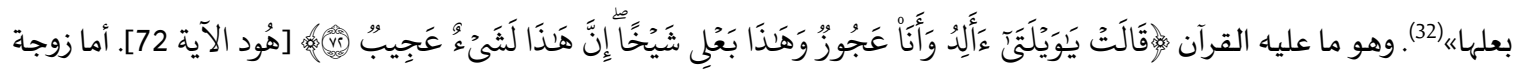

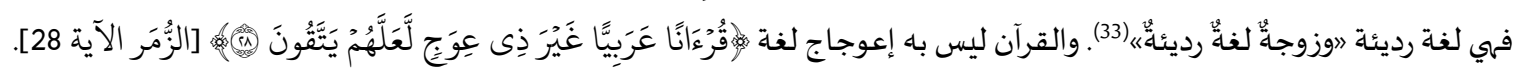

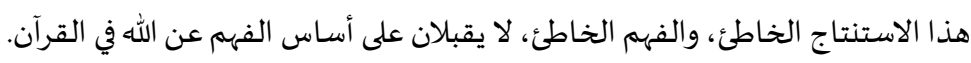

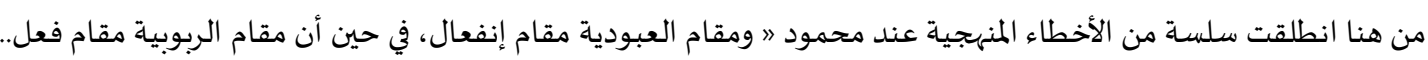

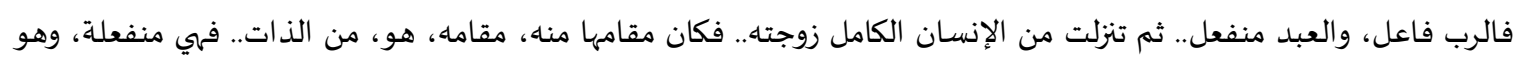

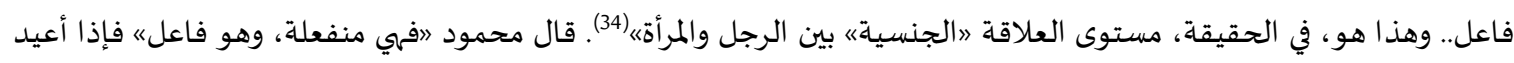

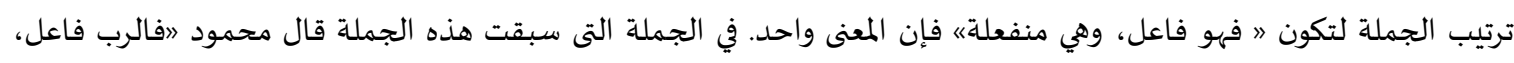

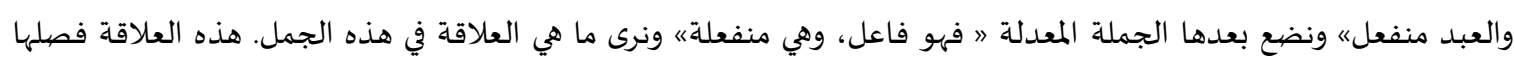

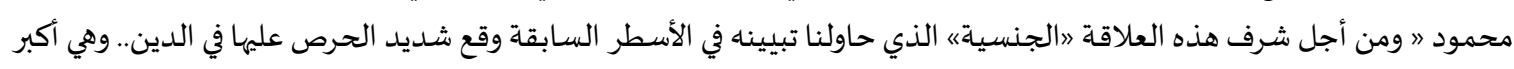

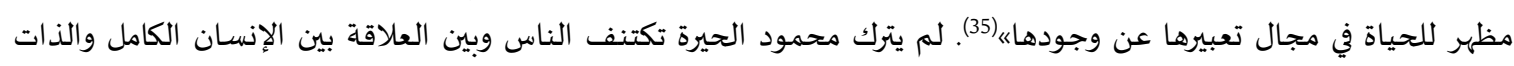

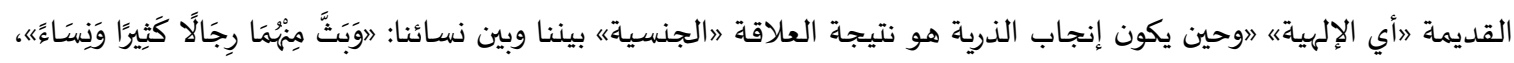

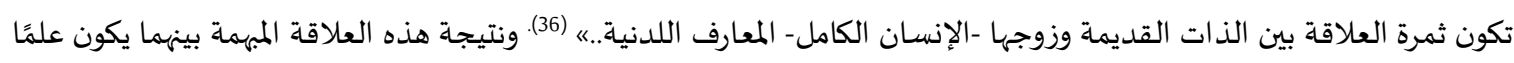

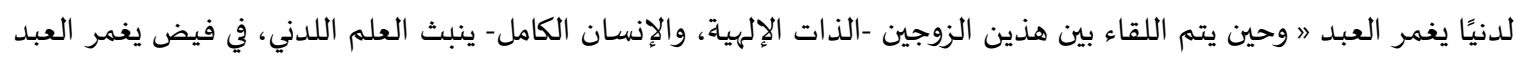

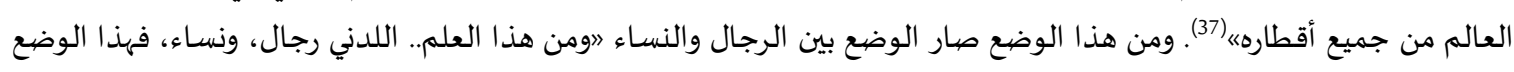

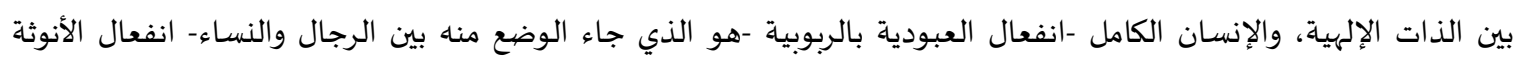

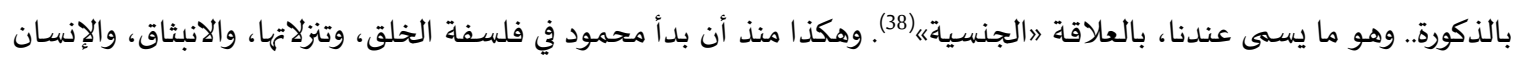

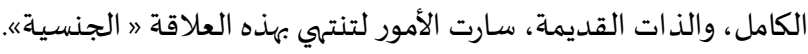

29 تطوير شريعة الأحوال الشخصية،مرجع السابق نفس الصفحة.

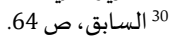

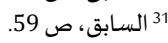

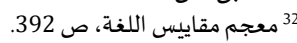

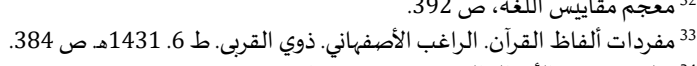

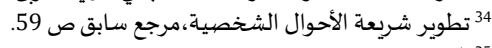

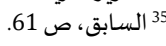

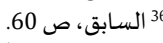
37 تطوير شريعة الأحوال الشخصياة، مرجع السابق نفس الصفحة. 38 السابق نفس الصفحة. 


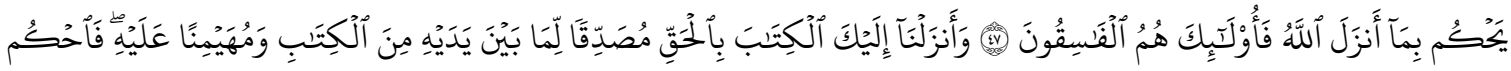

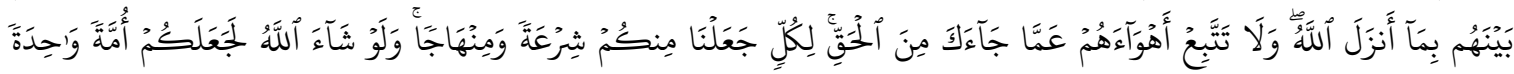

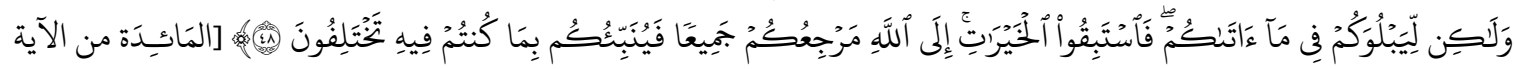

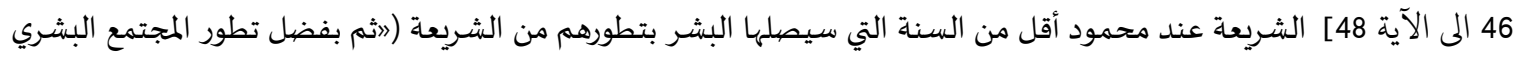

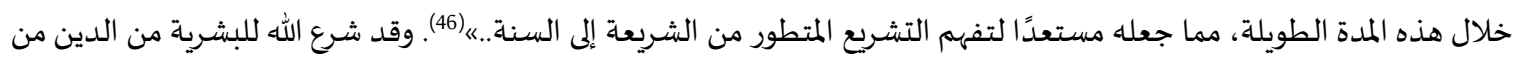

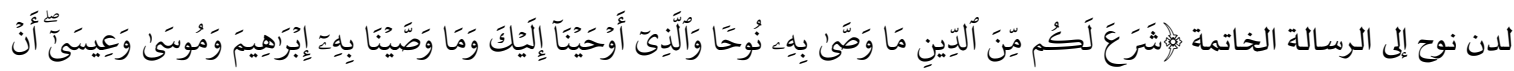

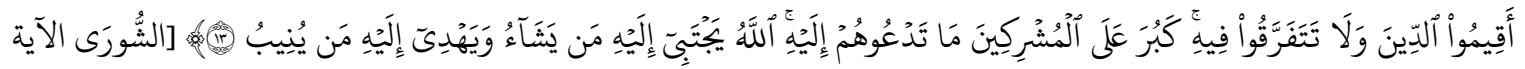

متن الكتاب تناول الزواج في الحقيقة مقابل الزواج في الشريعة، وبنفس الطريقة جعل الزواج في شريعة الأصيول مقابل الزواج في

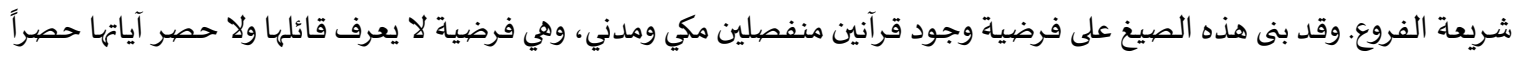

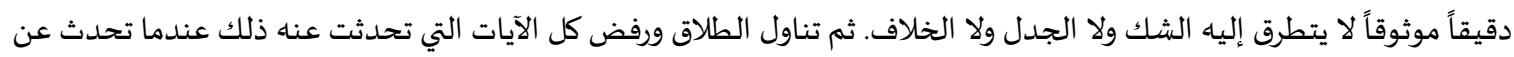

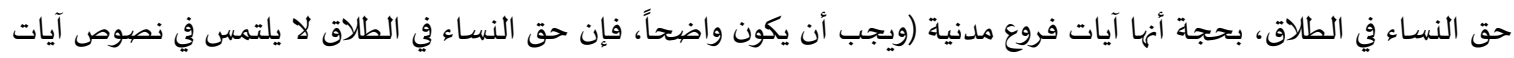

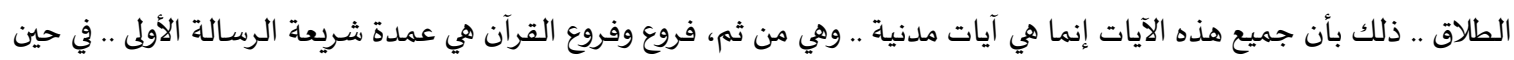

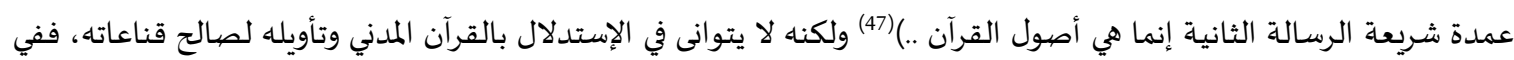

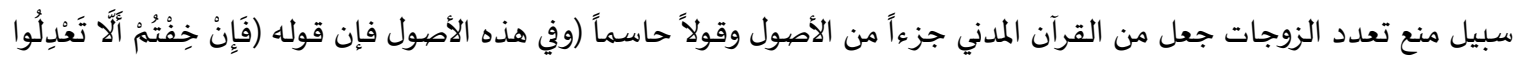

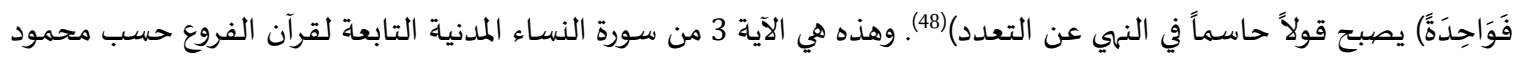

محمد طاه.

عموماً الكتاب ليست به منهجية واضحة ولا تطوير يحل مشكلات اليوم. لقد صمم الكتاب ليمنع الطلاق وتعدد الزوجات،

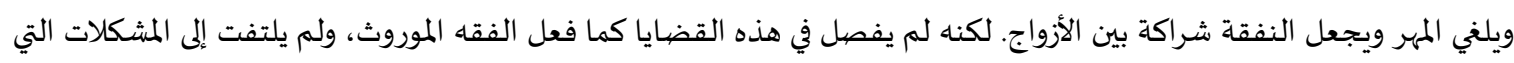

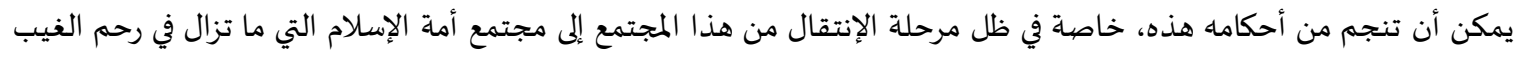

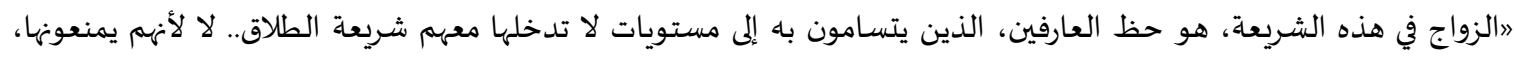

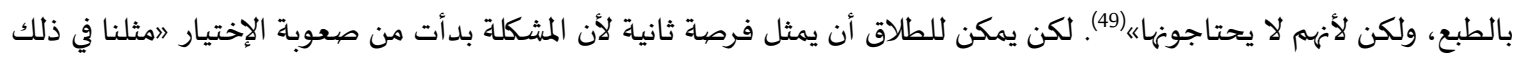

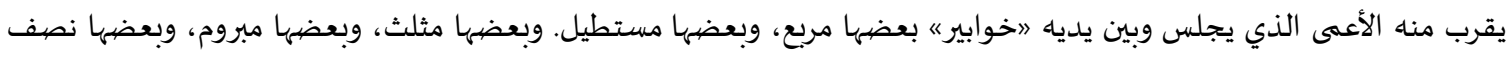

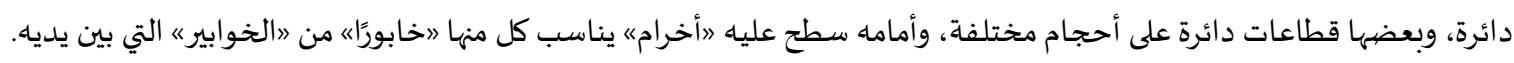

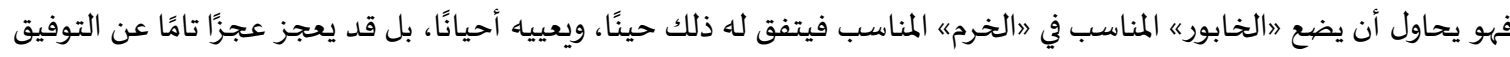

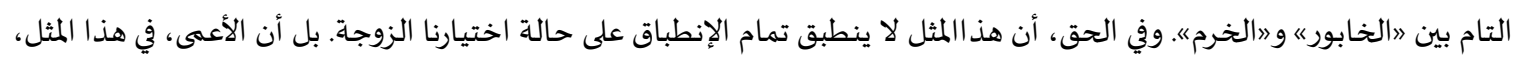

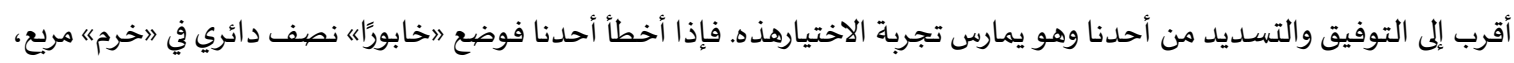

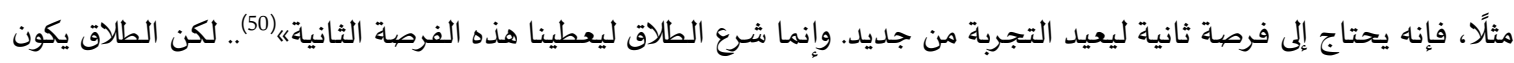

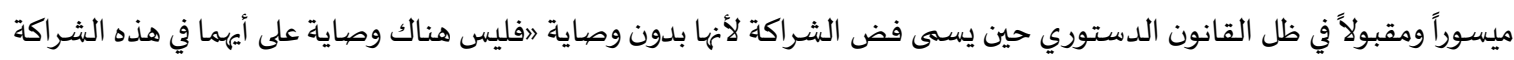

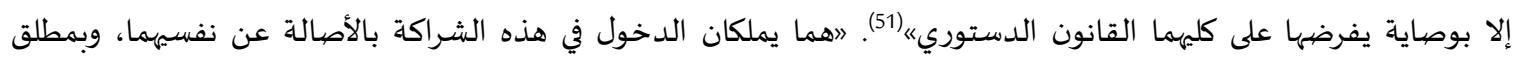

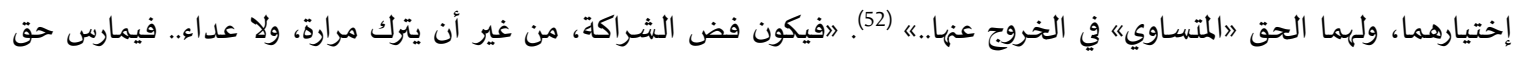
الطلاق في سعة أفق، وطيبة نفس، (53).

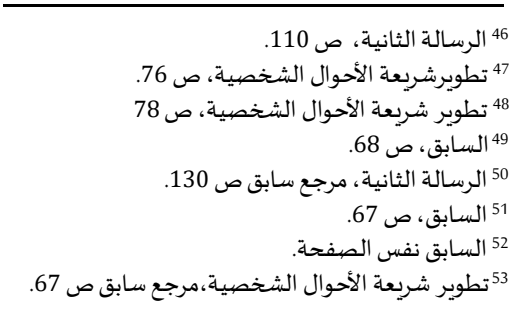


المبحث الثالث: مساواة المرأة بالرجل وعقد الزواج؛ مقدماته وشروط صحته ونفاذه وأحكامه في الفقه الإسلامي

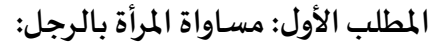

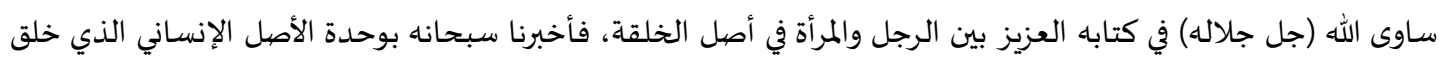

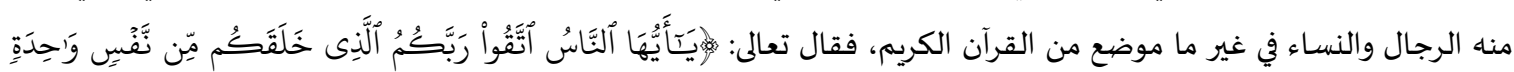

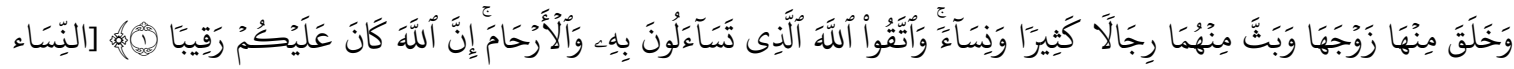

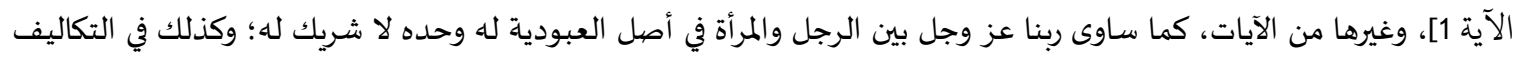

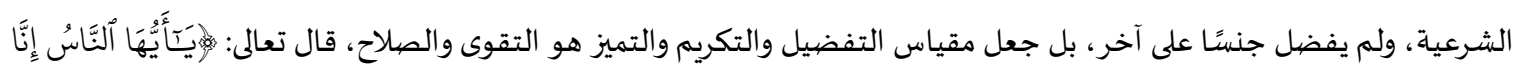

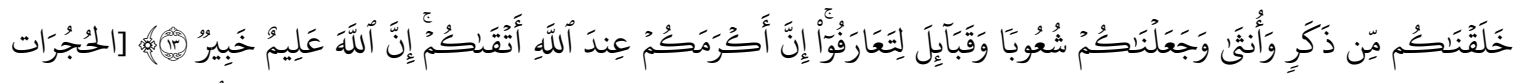

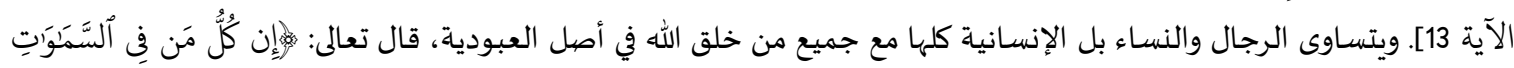

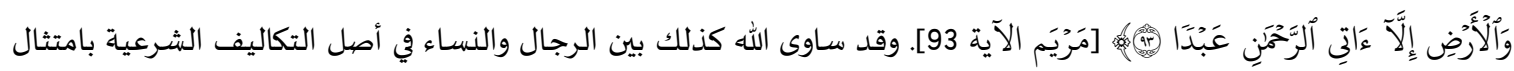

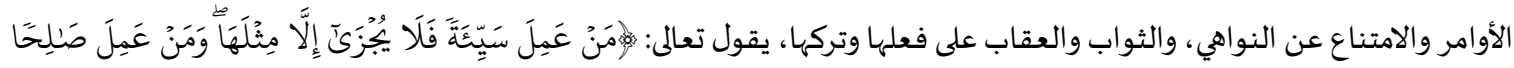

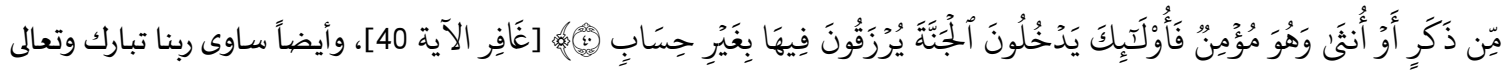

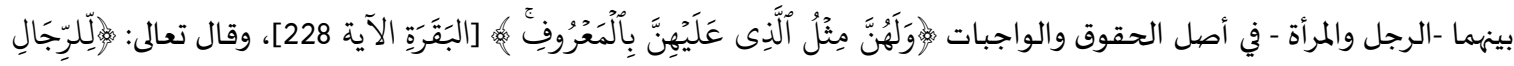

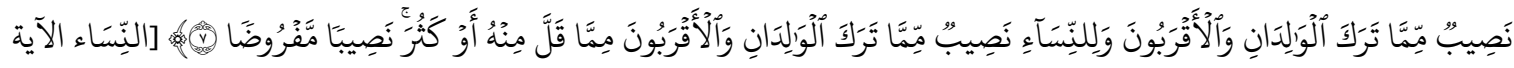

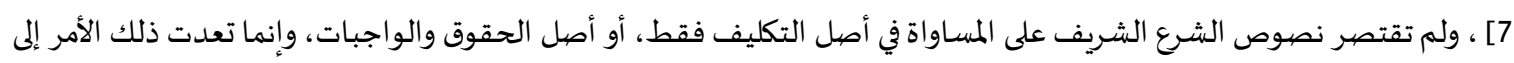

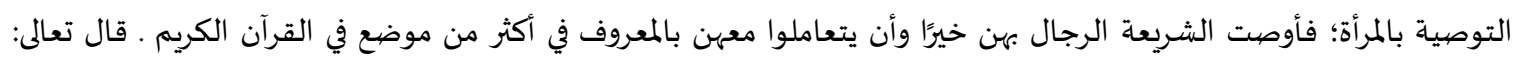

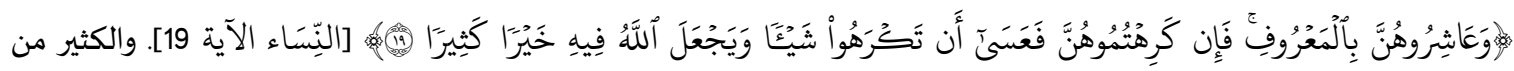

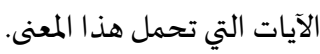

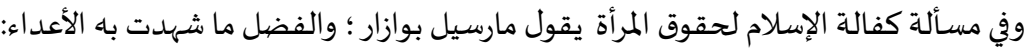

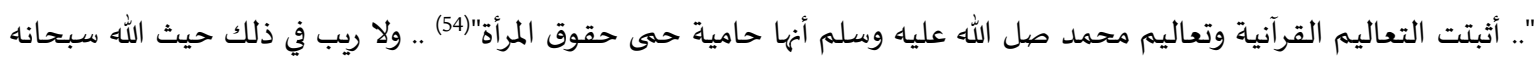

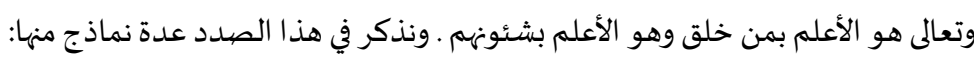

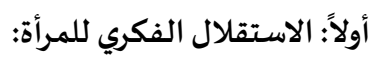

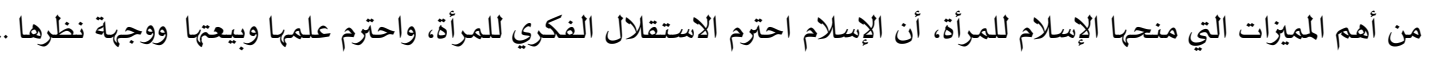

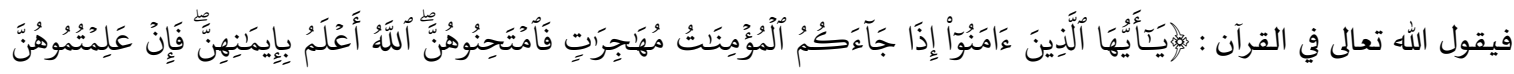

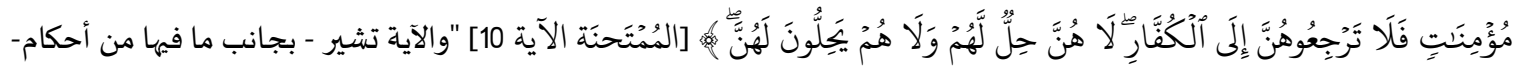

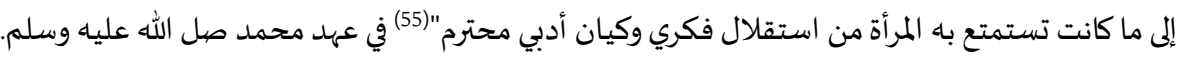

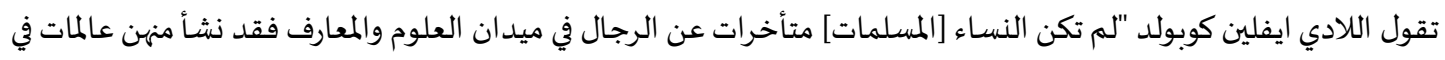

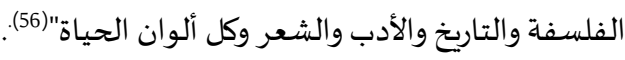

$$
\begin{aligned}
& \text { ثانياً: حقوق المرأة في أمور الزواج: }
\end{aligned}
$$

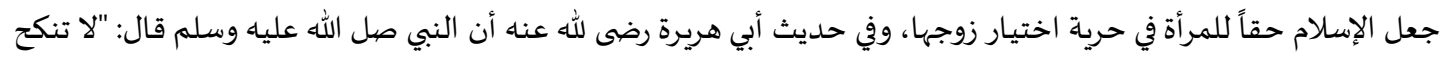

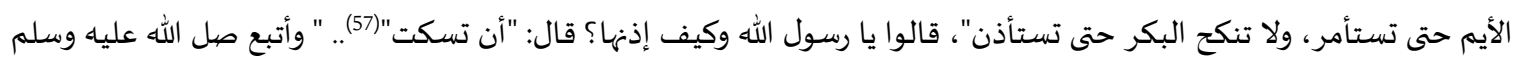

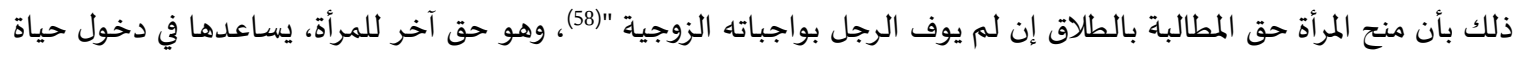

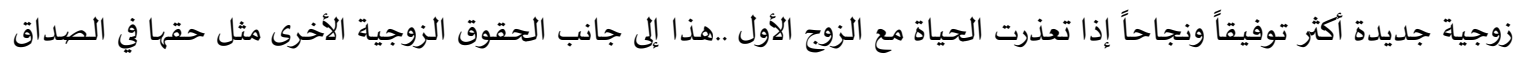

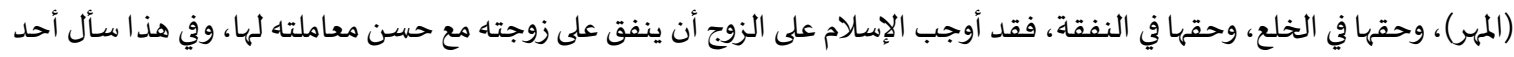

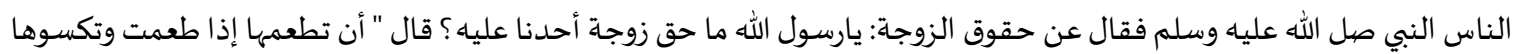

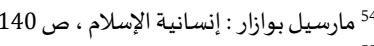

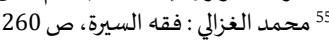

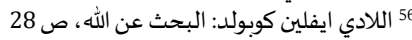

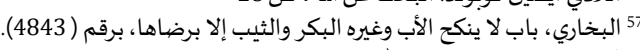

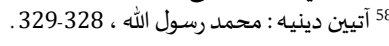


إذا اكتسيت ... ولا تضرب الوجه ولا تقبح ولا تهجر إلا في البيت "(59).. وعلى الرجل بما اختص به من صفة الرجولة، وقوة الجلد،

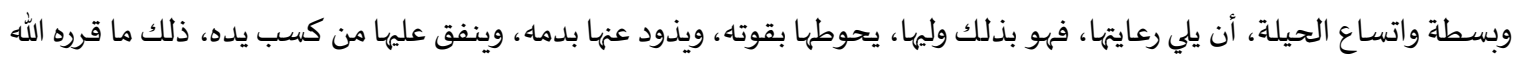
تعالى بقوله:

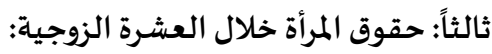
قررت الشريعة الإسلامية للمرأة جملة من الحقوق -قمة في العدل المراة والإنصاف-، فللمرأة خلال قيام العشرة الزوجية حقوقها المشروعة، ومتى أخل زوجها بشيء من تلك الحقوق كان لها المطالبة بحقوقها عبر القضياء. ومن أنواع المطالبات التي يمكن للمرأة المطالبة بهاء قضياءً: المطالبة بالصداق أو ما بقي منـاء. المطالبة بإنفاذ الشروط التي اشترطتها الزوجة عند العقد.

$$
\text { المطالبة بإحسان العشرة فيما لو أسـاء الزوج عشرتها. }
$$$$
\text { المطالبة بحق السكن فيما لو منعها الزوج من هذا الحق أو أخل باء. }
$$

المطالبة بالنفقة.

وإذا امتنع الزوج عن بذلها فإن للزوجة رفع الدعوى أمام المحكمة المختصةة -المحاكم الشرعية- للمطالبة بها وفق الإجراءات

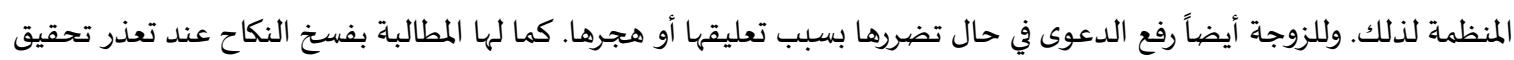
المصالح المرجوة في الزواج والتي بينتها الشريعة . ومن ذلك أيضاً حقوقها عند انتهاء العشرة الزوجية ومنها: وثيقة الطلاق لها أهميتها، والمطلَّقة أحق باستلام هذه الوثيقة حال إثبات الطلاق، يمكن توثيق الشروط بين الزوجين عند الطلاق على عوض.وإسقاط اسم المطلقة من دفتر عائلة زوجها الذي طلقها وفي إني

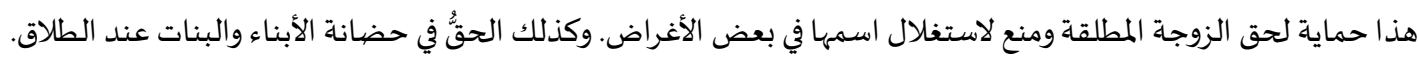

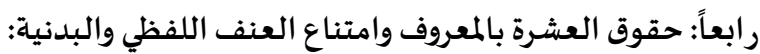

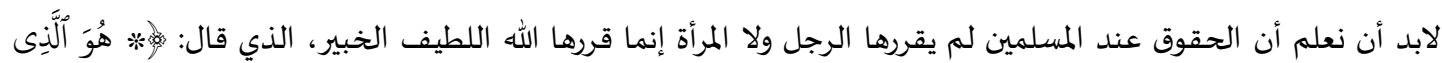

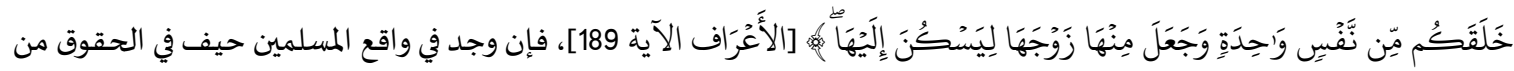

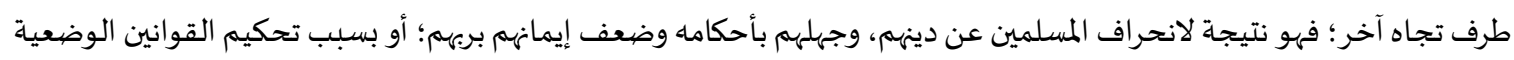
فيهم، أو بسبب تحكم الأعراف والتقاليد المخالفة للشرع في أحوالهم. والعلاقة بين الرجل والمراف والمرأة في المجتمع الإسلامي وداخل الأسرة

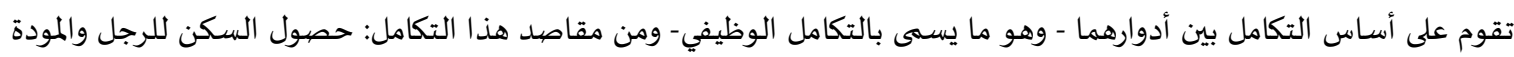

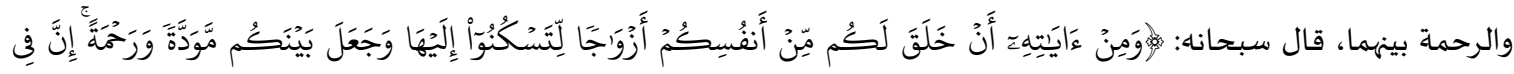

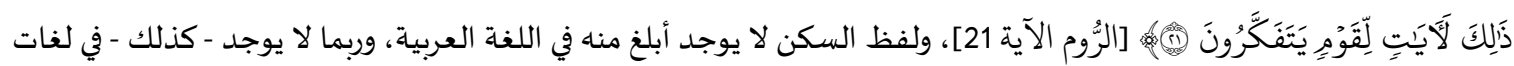

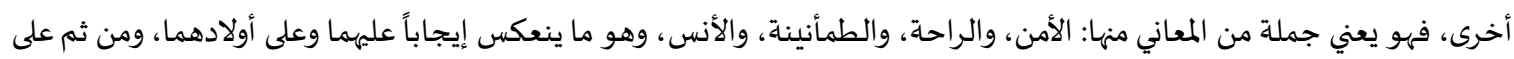
المجتمع كافة. المطلب الثاني: مسؤولية الرجل والمرأة في بناء الأسرة:

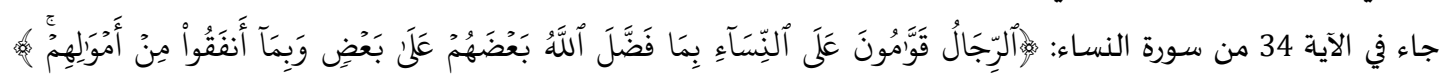

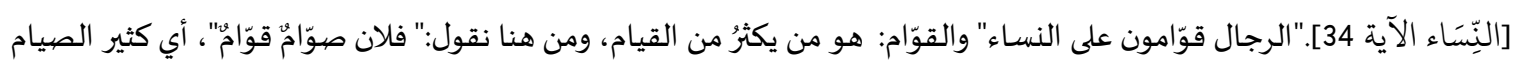

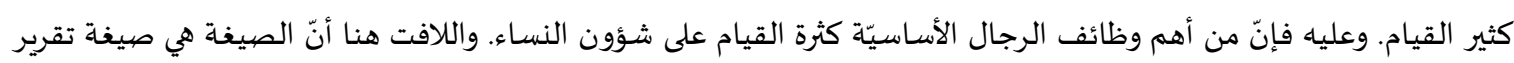

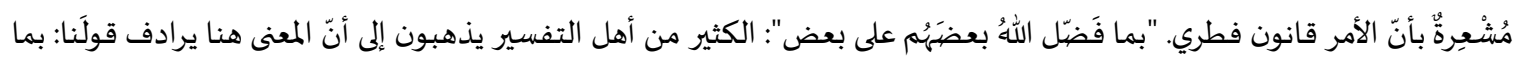

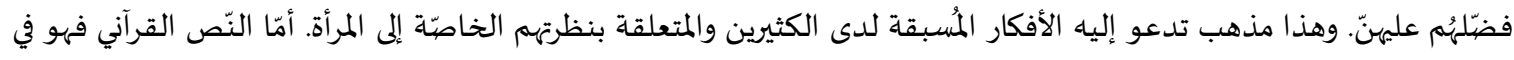

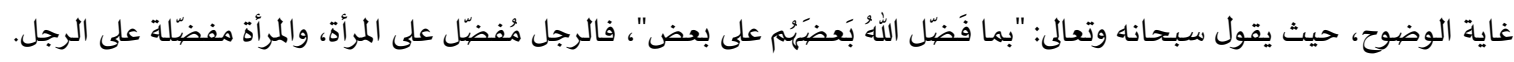

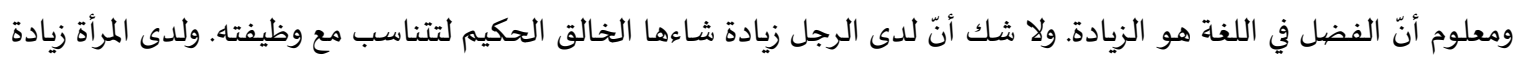

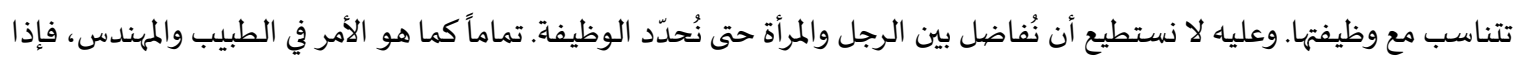

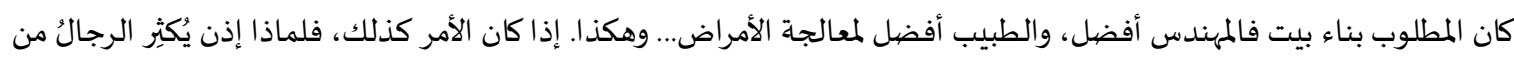

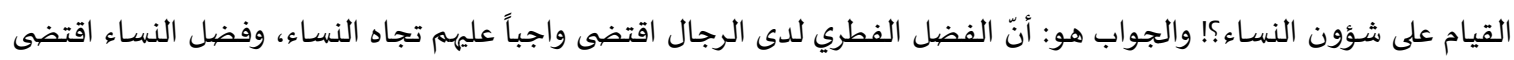




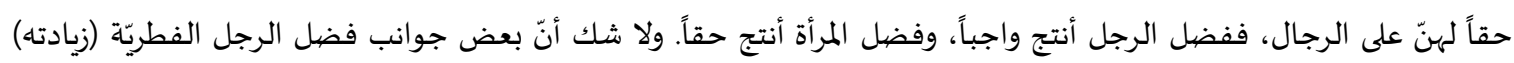

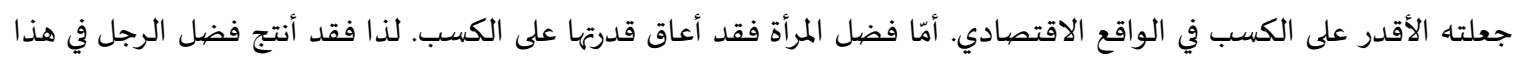

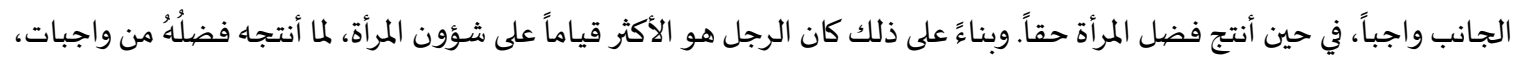

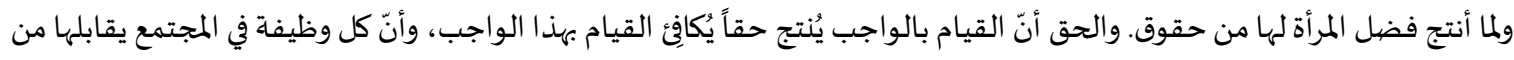

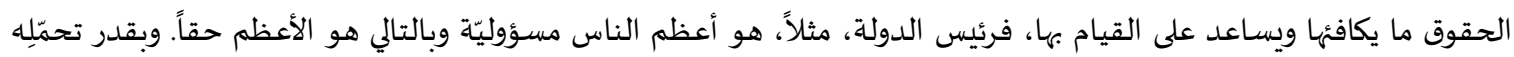

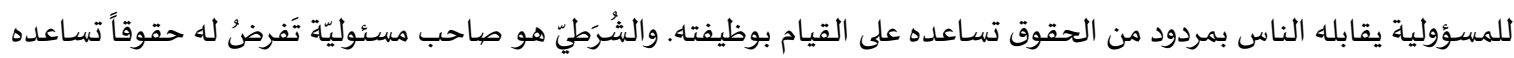

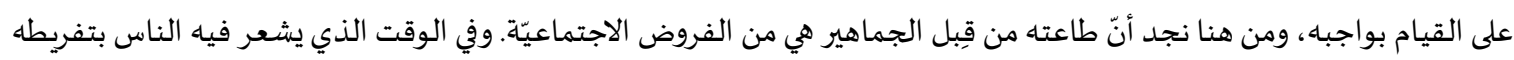

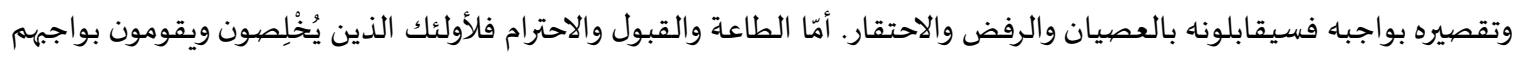

خير قيام.

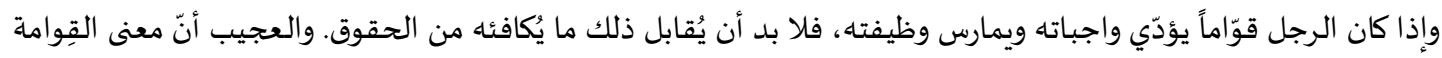

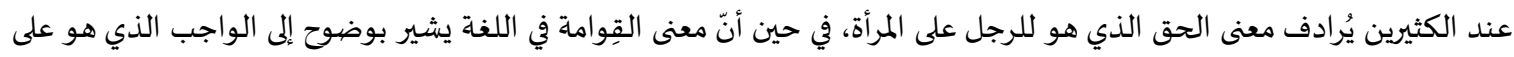

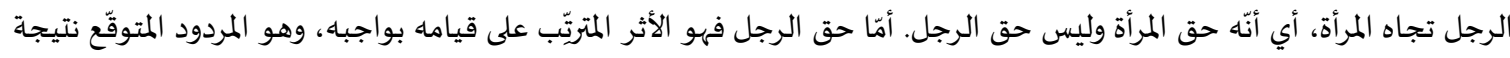

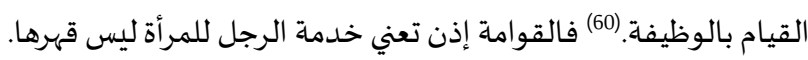

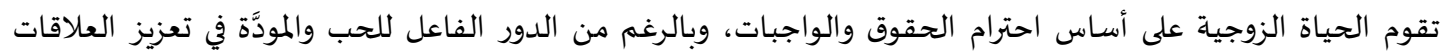

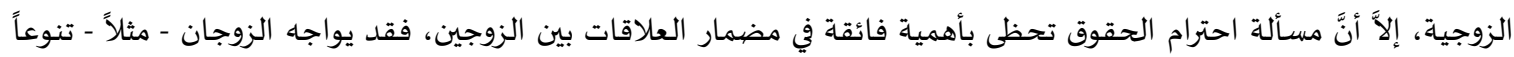

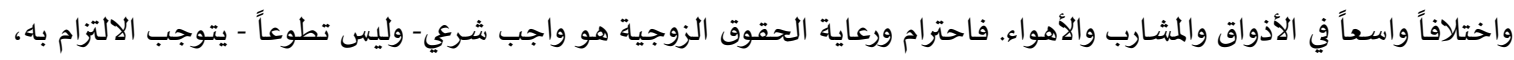

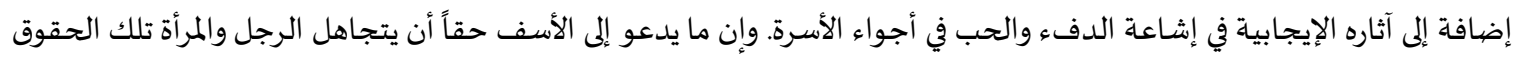

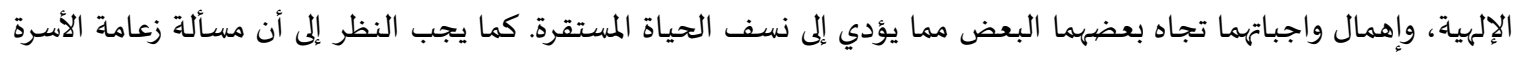

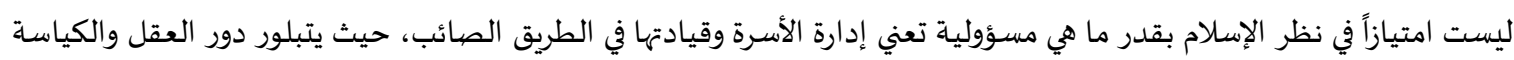

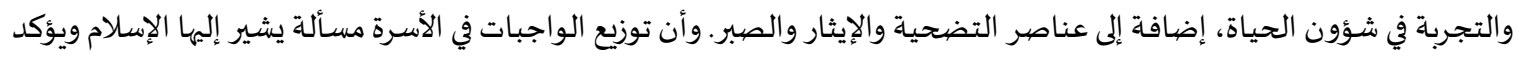

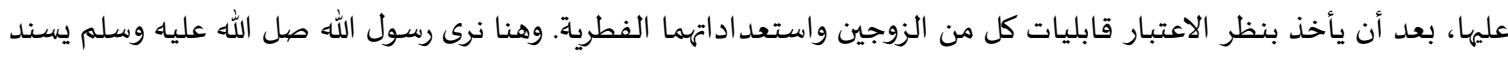

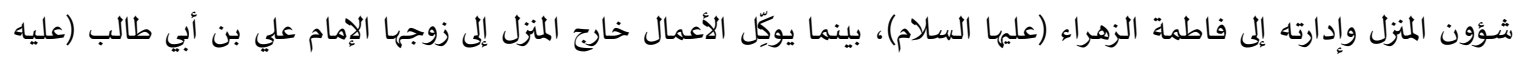

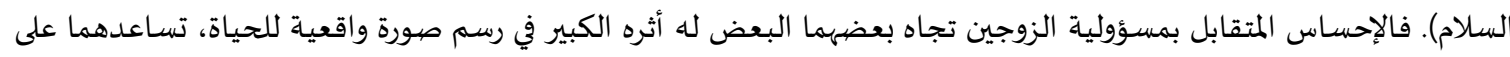

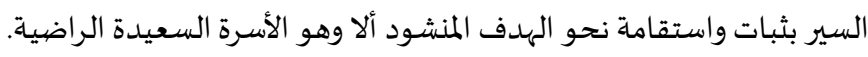

المطلب الثالث: حول تعدد الزوجات(61):

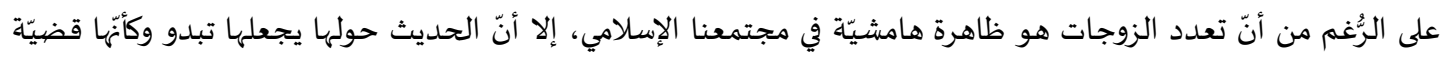

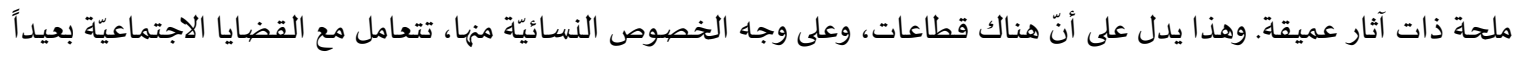

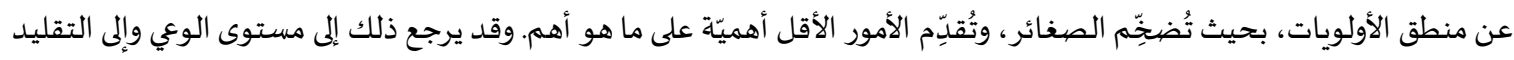

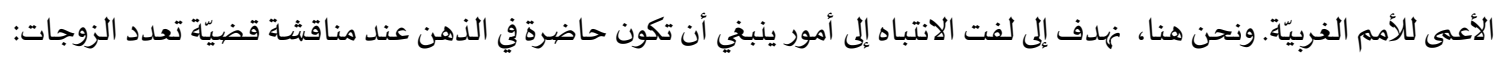

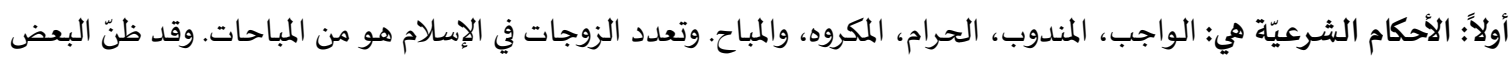

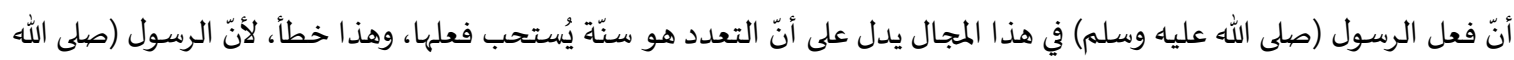

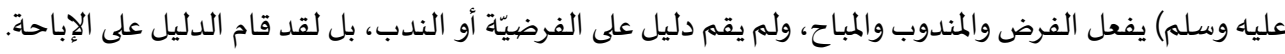

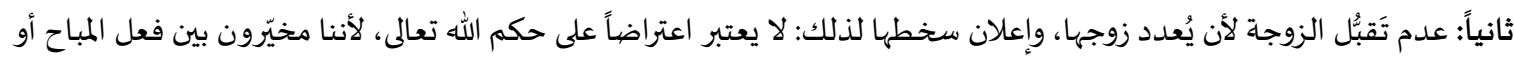

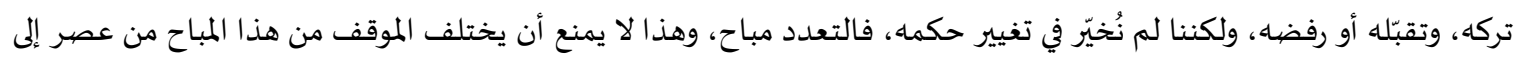
عصر، أو من مجتمع إلى مجتمع.

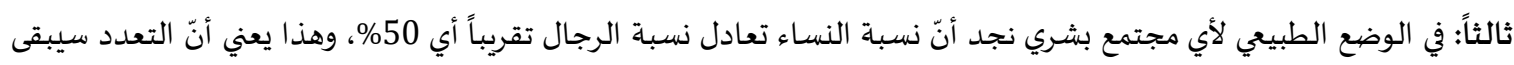

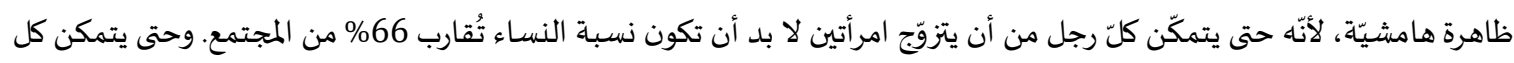

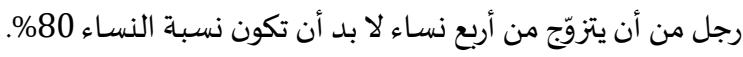




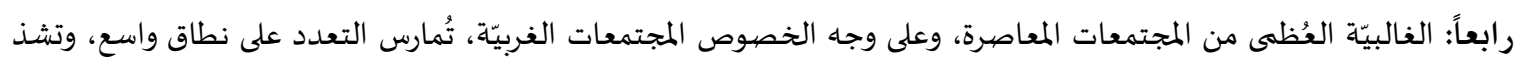

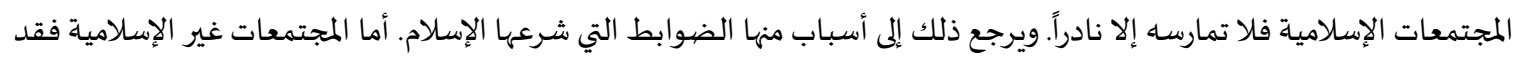

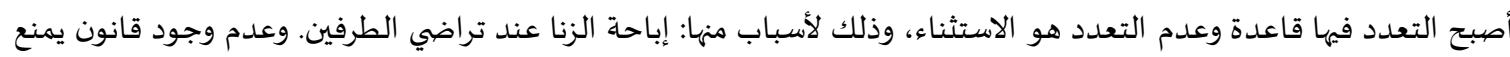

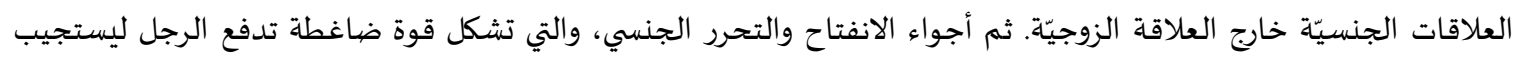

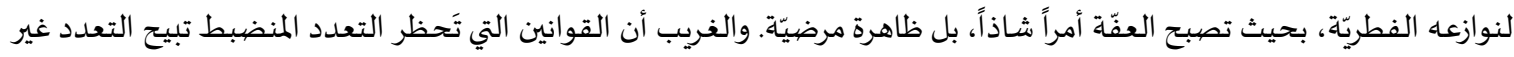
المنضبط في الغرب.

هذه بعض الملاحظات التي ينبغي أن تكون في عقل كل من يريد أن يبحث قضيّة تعدد الزوجات، وإننا لنعجب من منطق أولئك

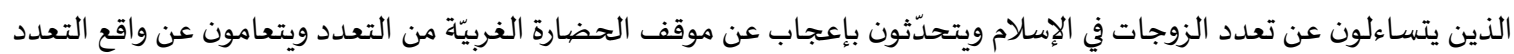

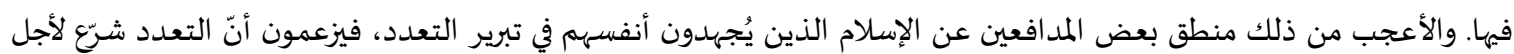

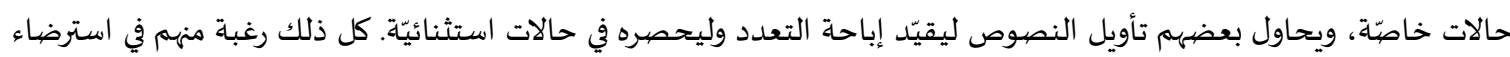

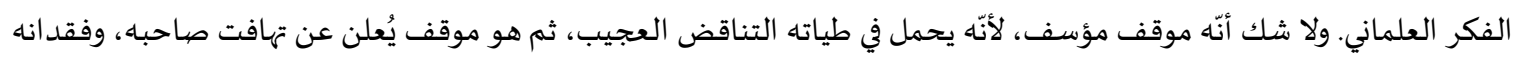

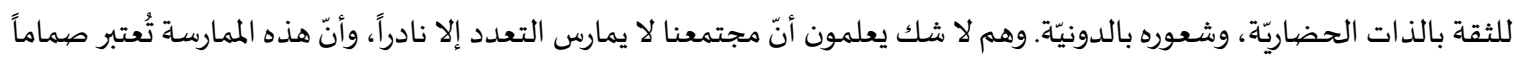

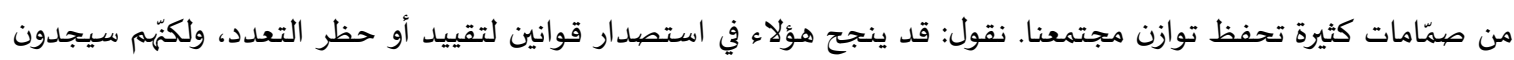

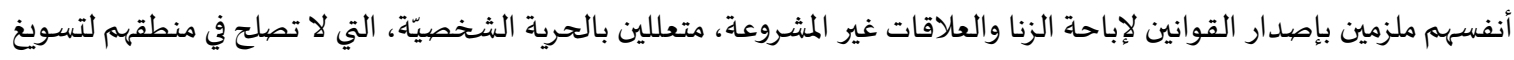

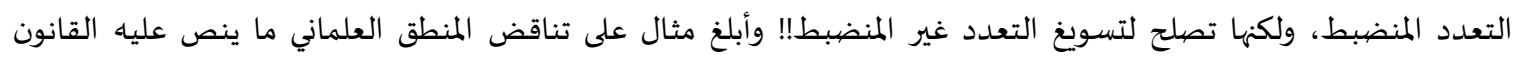

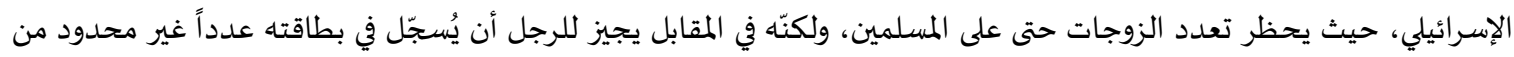

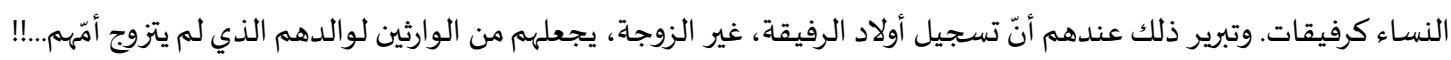

المبحث الر ابع: الطلاق و آثاره

المطلب الأول: تعريف الطلاق: الماق: الماق

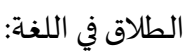

الطلاق لغة : الإرسال ورفع القيد والمفارقة. (62) ، وإن كان العرف يخص الطلاق برفع القيد المعنوي ، والأطلاق برفع القيد الحسي (63). الطلاق في الاصطلاح:

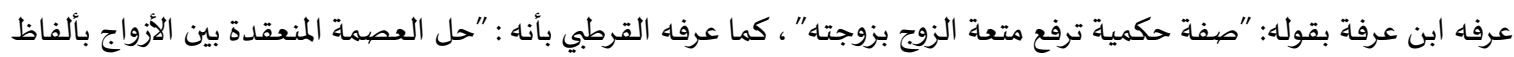

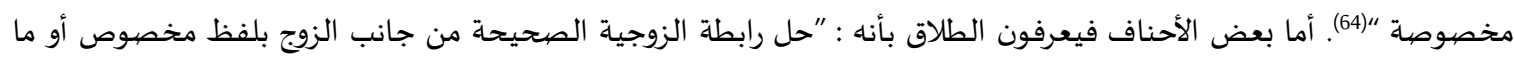

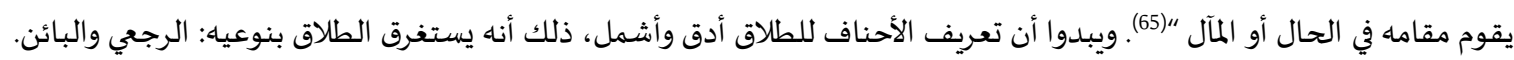

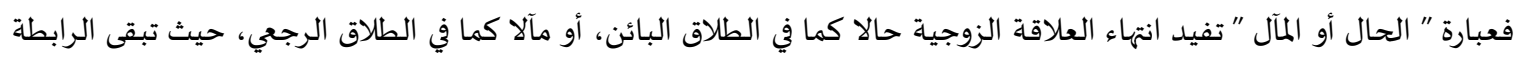

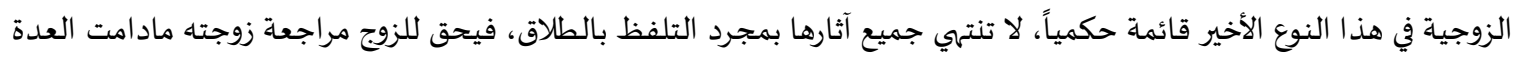

قائمة.

المطلب الثاني: مشروعية الطلاق وحكمه: إن الزواج شرع ليكون عقداً أبدياً، ولا ينتهي إلا استثناء عندما تقتضيه الضرورة القصيوى، لذلك أمر الله سبحانه وتعالى الأزواج

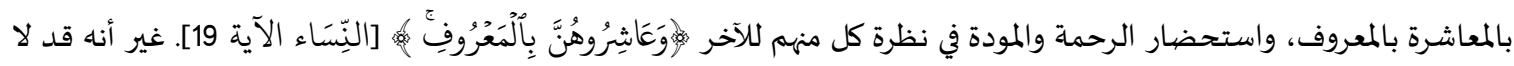

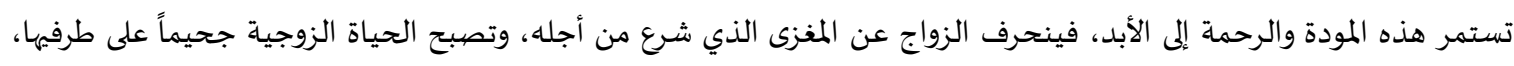

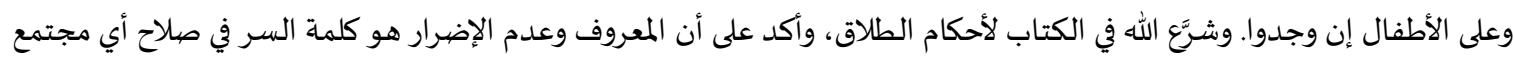

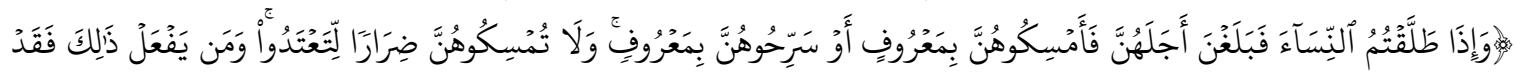

62 التعريفات ص : 183 ، أورده محمد بشير الشقفة ، الفقه المالكي في ثوبه الجديد ، الجزء الرابع : فقه الأحوال الشخصية كتاب الطلاق ، الطبعة الأولى 2003 م ، دار البشير ص : 63 محمد مصططى شلبي ، أحكام الأسرة في الإسلام دراسة مقارنة بين فقه المذاهب السنية والمذهب الجعفري والقانون ، الطبعة الرابعة 1983 ، الدار الجامعية للطباعة والنشر ، 


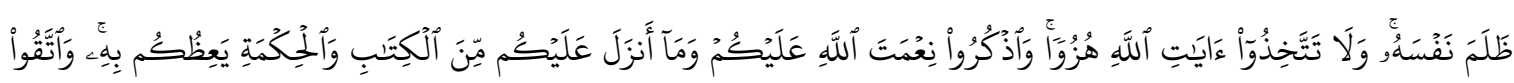

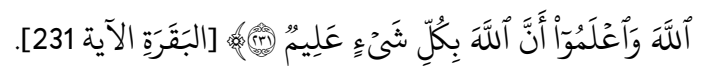

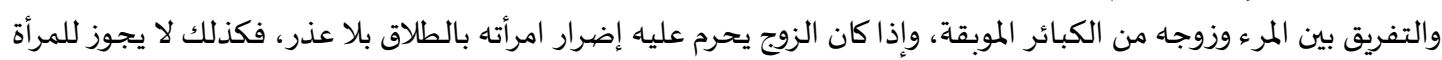

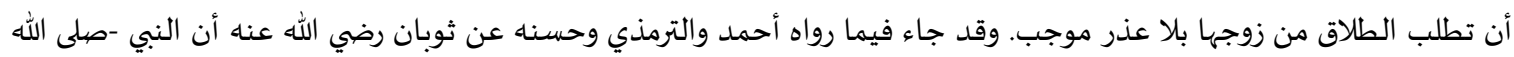

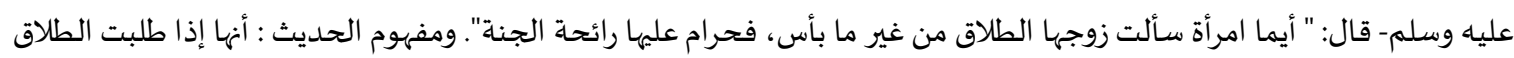
من بأس وبسبب، فلا إثم عليها.

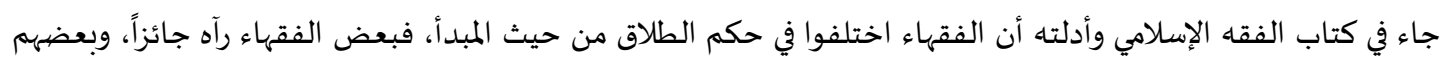

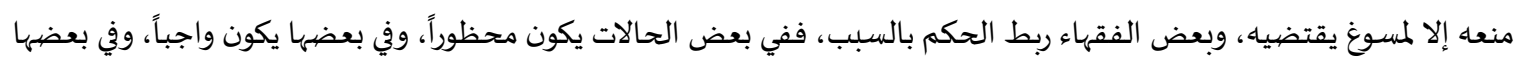

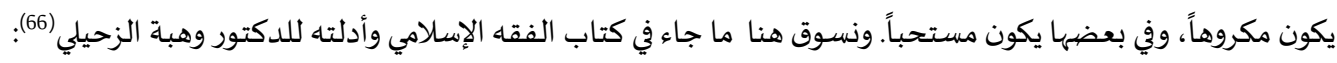

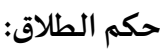

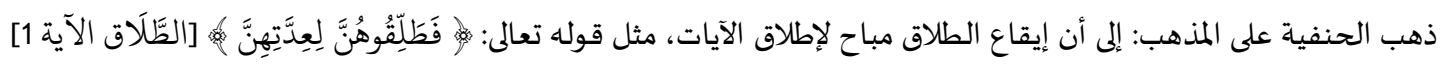

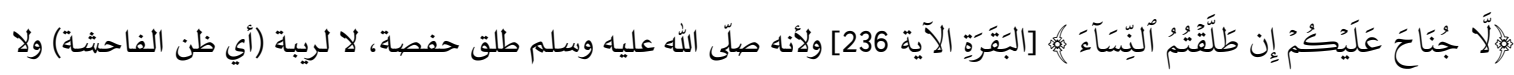

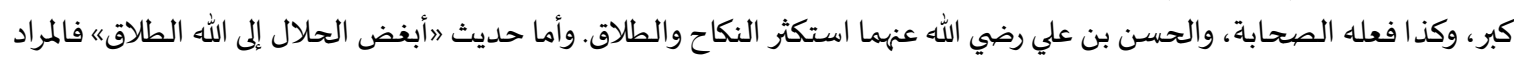

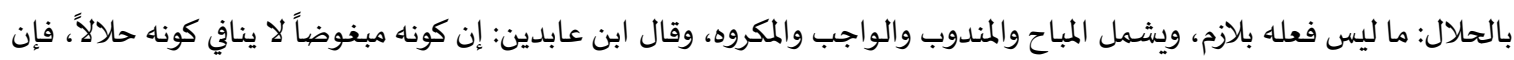

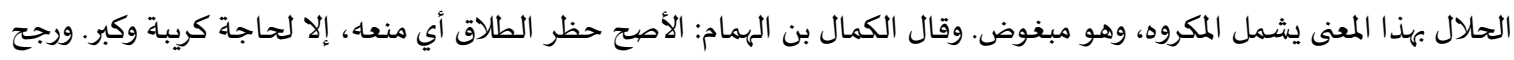

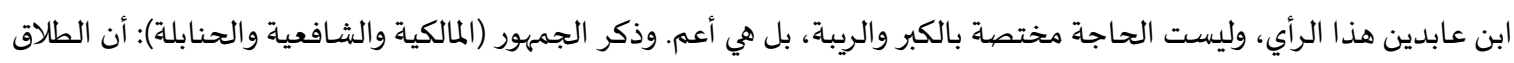

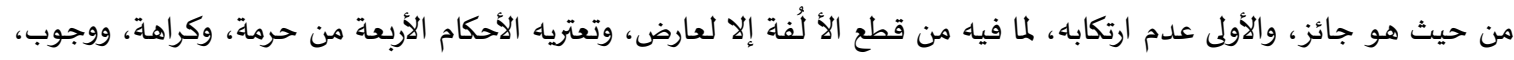
وندب، والأصل أنه خلاف الأولى الن.

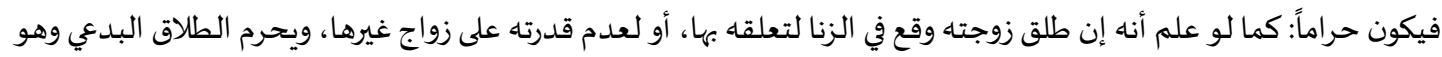

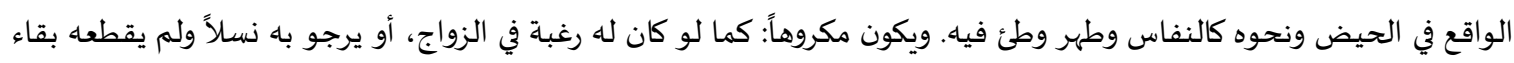

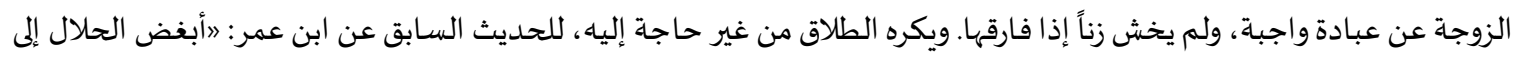

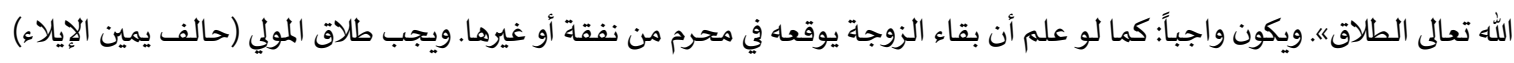

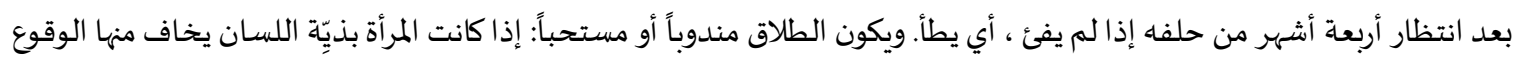

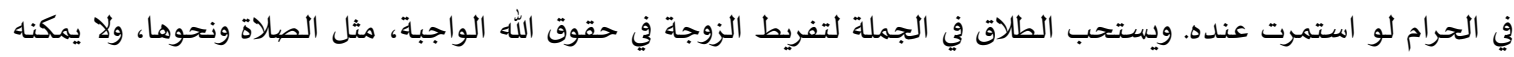

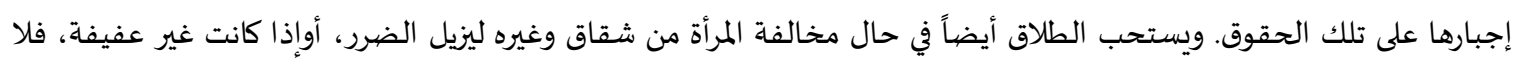

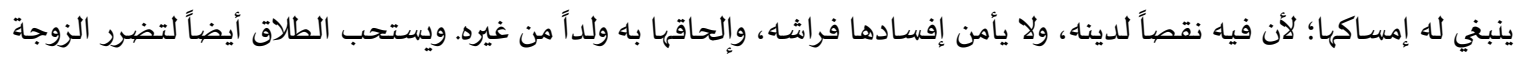
ببقاء النكاح لبغض أو غيره.

المطلب الثالث: طلاق المرأة نفسها:

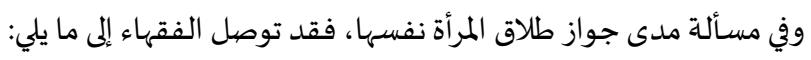

أولاً: أن الطلاق من حيث الأساس حق أعطاه الإسلام للرجل.

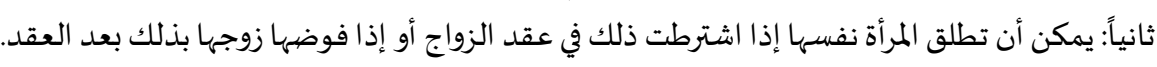

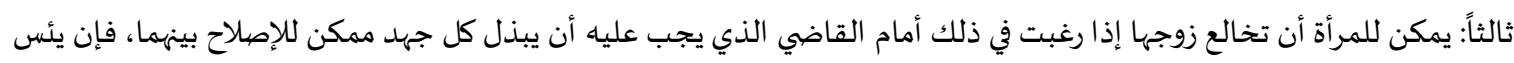
قضى بالخلع. رابعاً: يمكن للمرأة أن تتفق مع زوجها على الطلاق ضمن أي شروط مشروعة يتراضيان عليها.

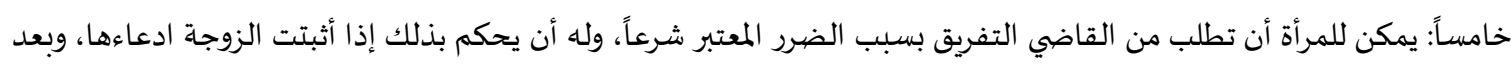

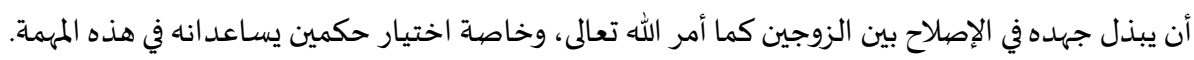

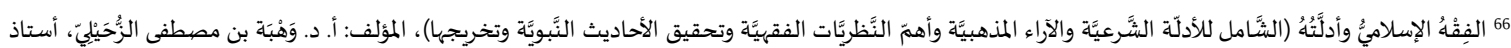

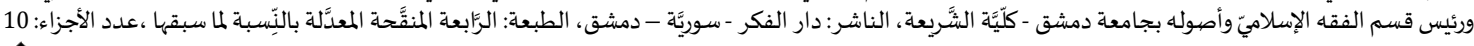


المبحث الخامس: نماذج من أوجه الإختلافات والتماثلات بين آراء محمود محمد طه والمذاهب الفقهية في مسائل

الأحوال الشخصية.

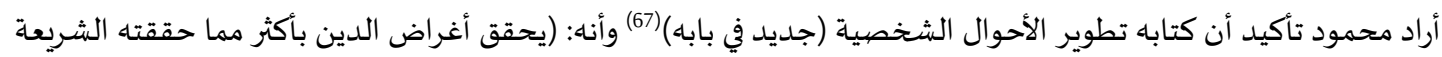

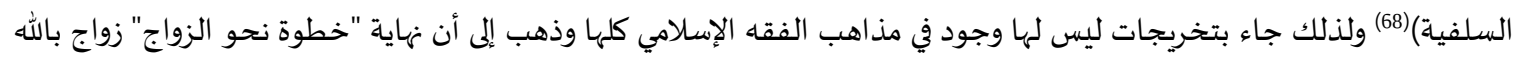

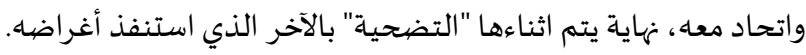

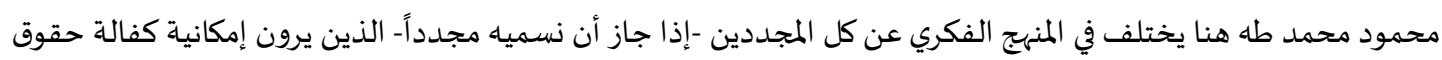

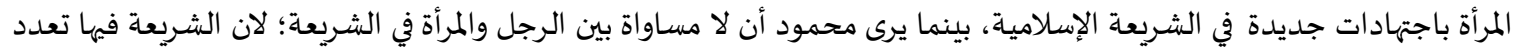

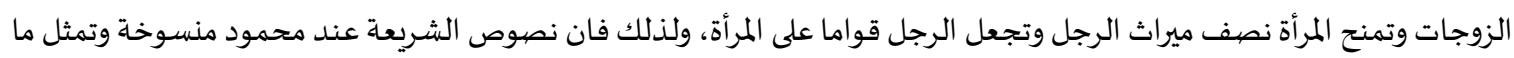

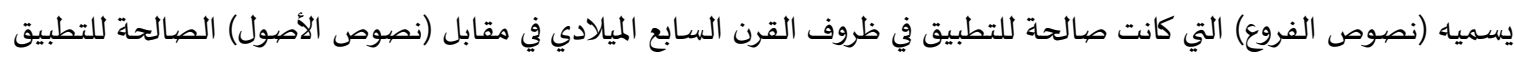

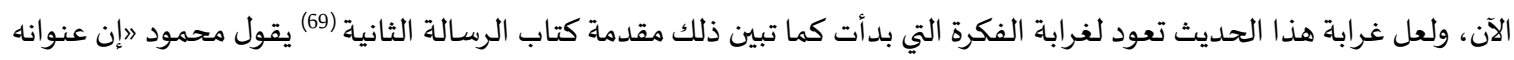

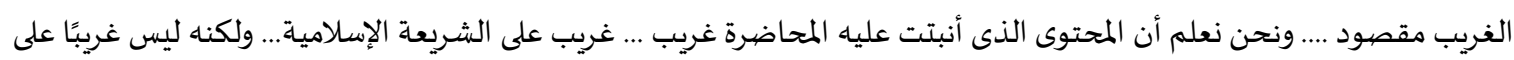

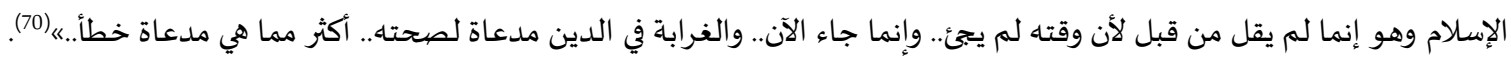

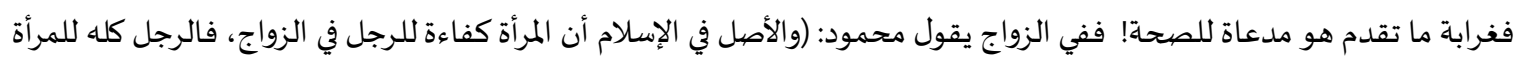

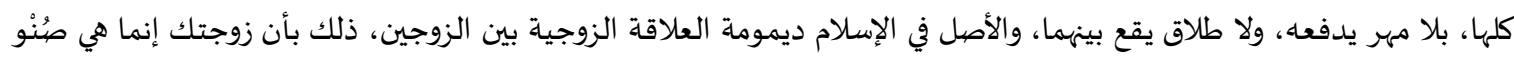

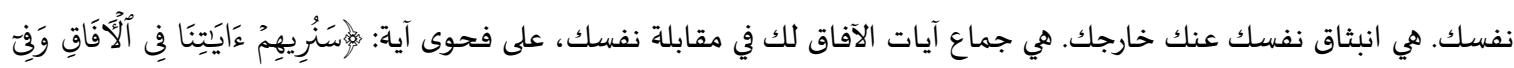

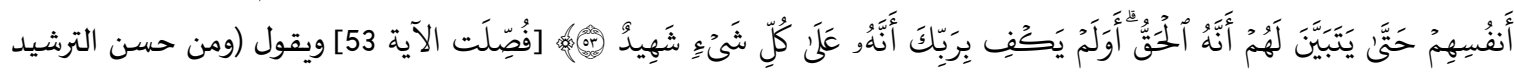

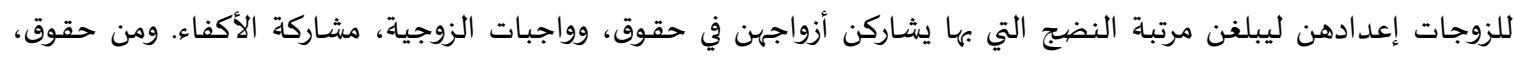

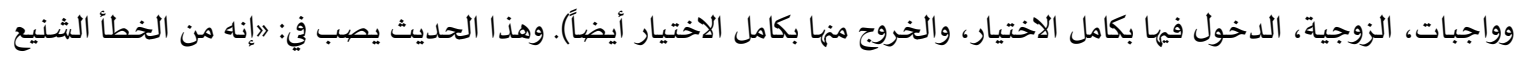

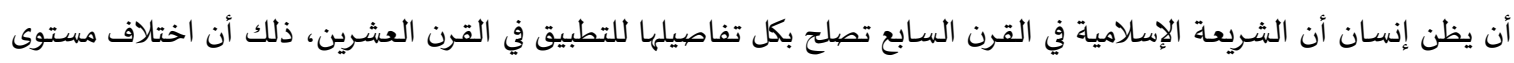

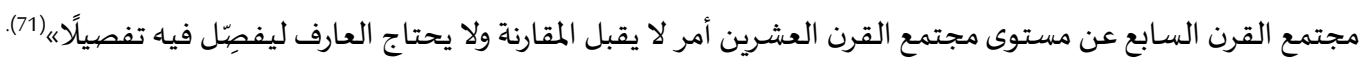

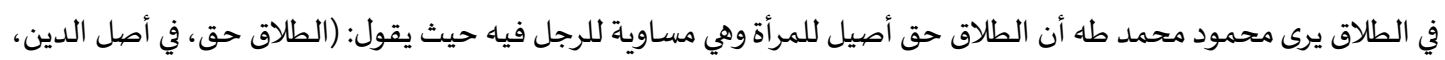

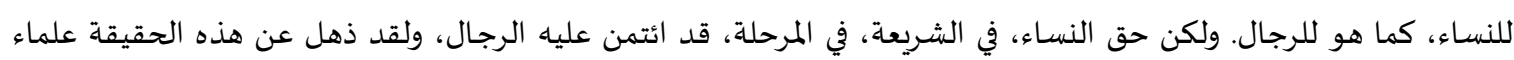

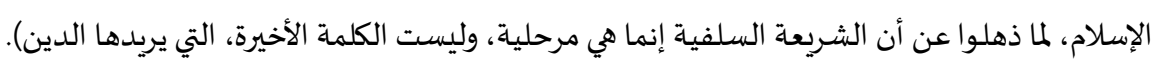

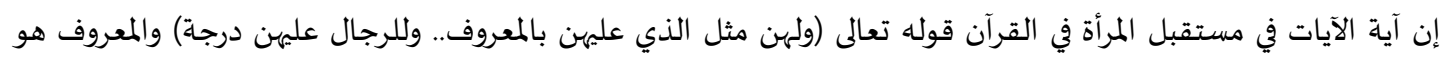

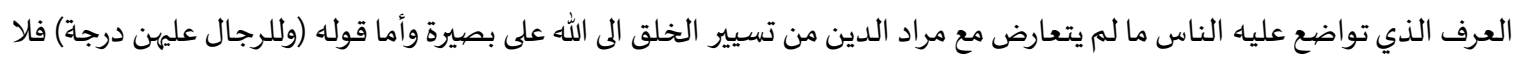

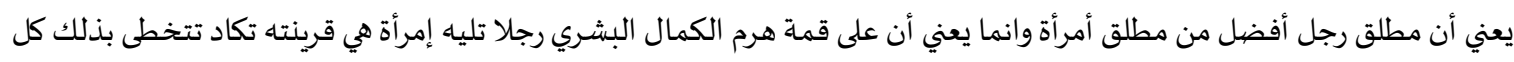

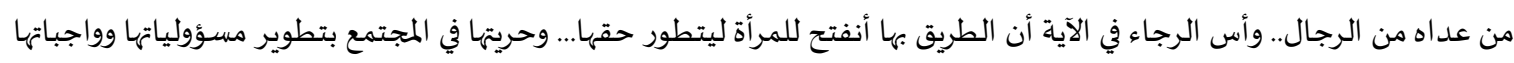

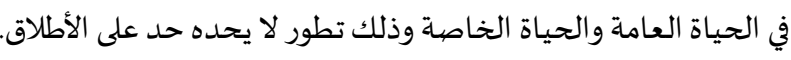

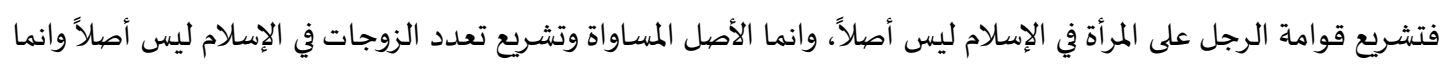

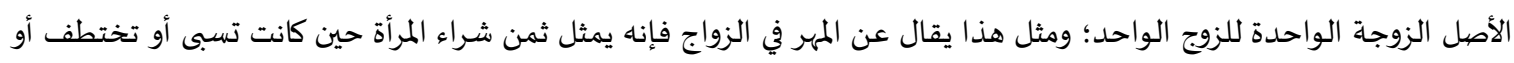

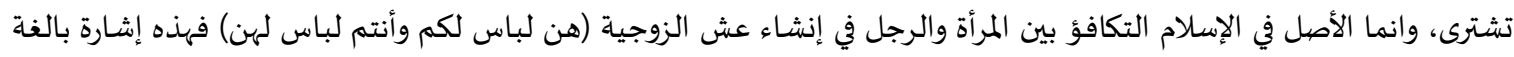

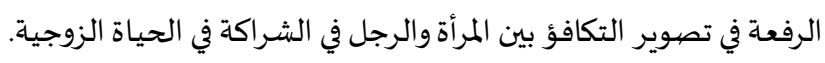

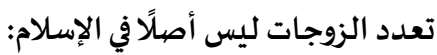

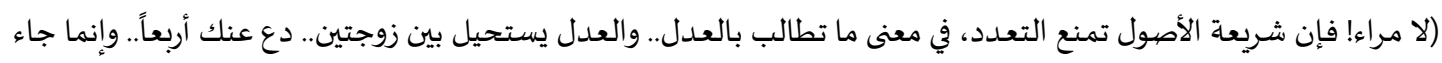

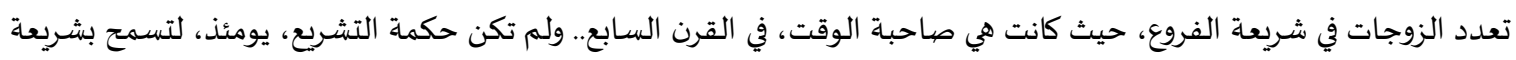

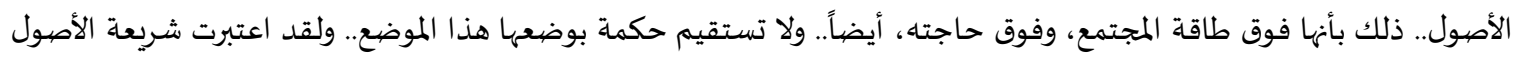

67 تطوير شريعة الأحوال الشخصية، سابق، ص 6.

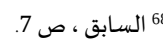

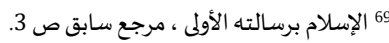

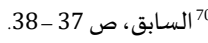

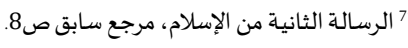


مدخرة ليومها، ولقد جاء هذا اليوم بمجيء مجتمعنا هذا الكوكبي الذي يسعى لإقامة الحكومة العالمية التي تقوم على الدستور

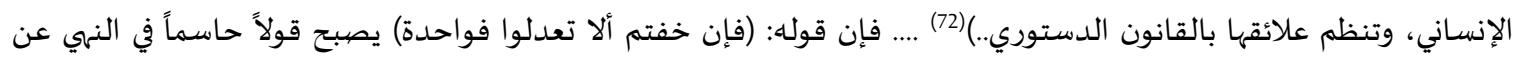

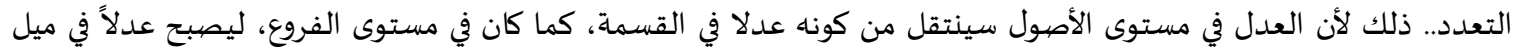

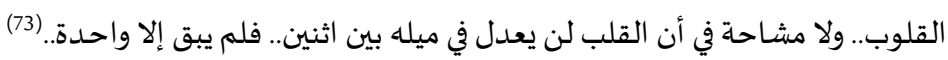

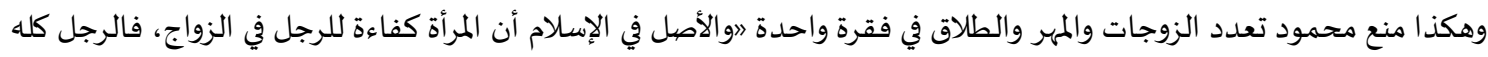

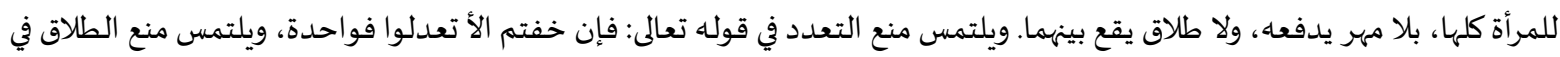

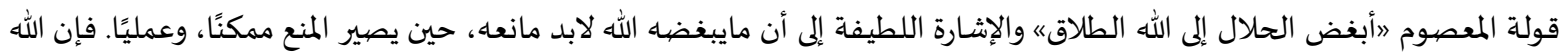

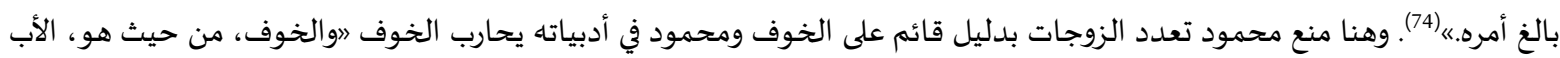

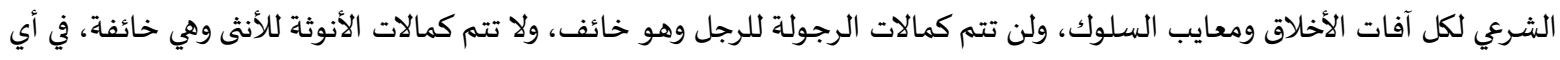

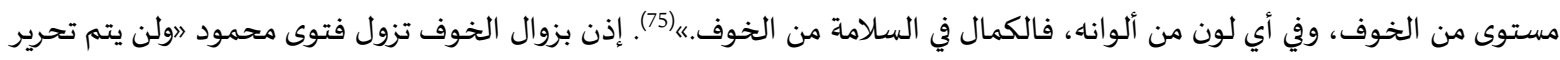

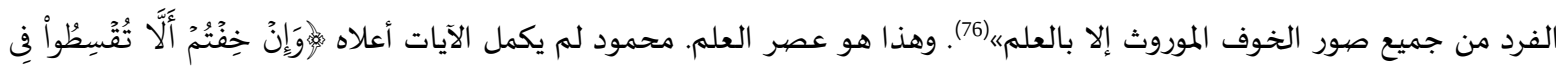

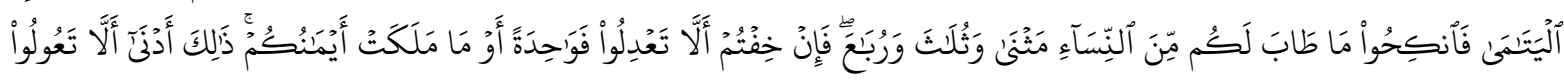

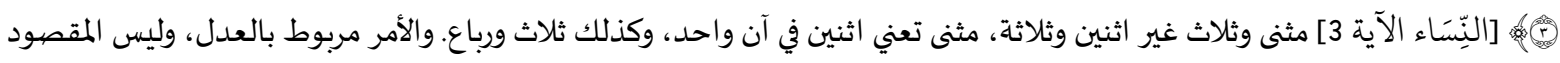

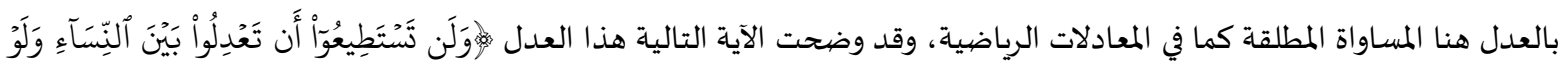

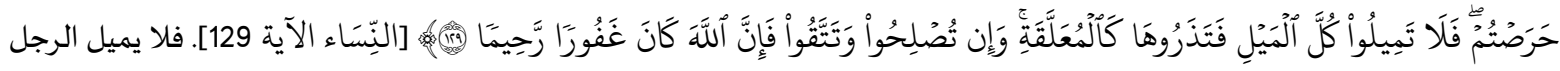

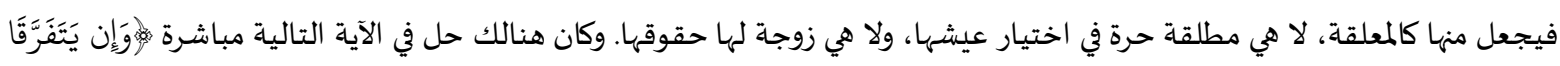

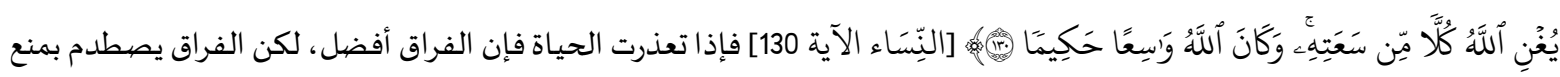

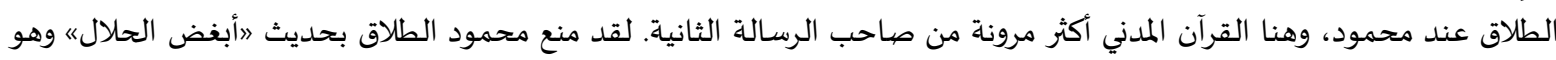

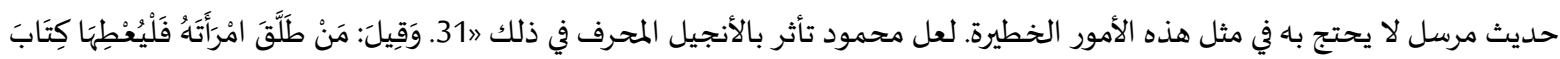

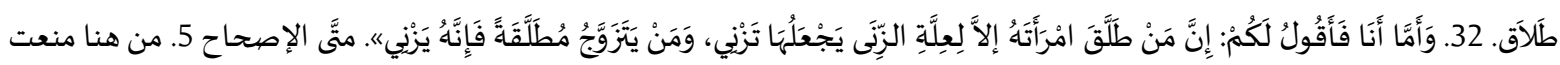

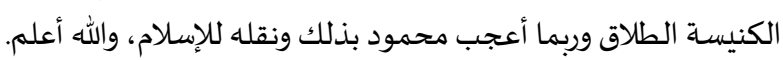
لعل أخطر ما ذهب إليه محمود هو قطعه أن الله سيحرم في المستقبل ما هو يكرهاه " والإشارة اللطيفة إلى أن مايبغضاه الله لابد اللابد

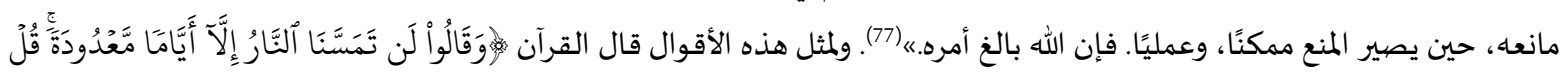

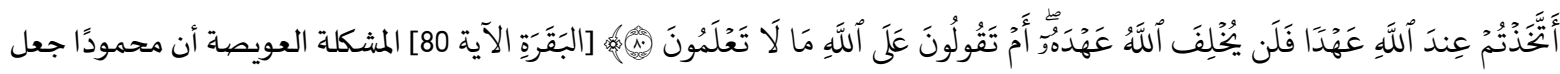

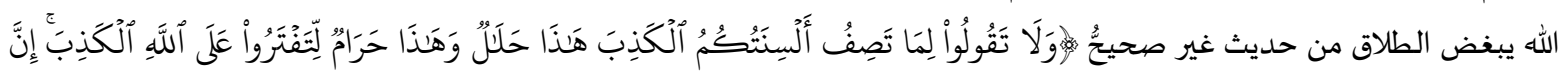

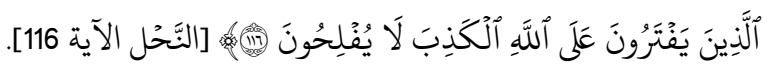

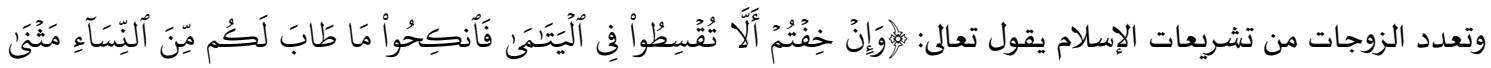

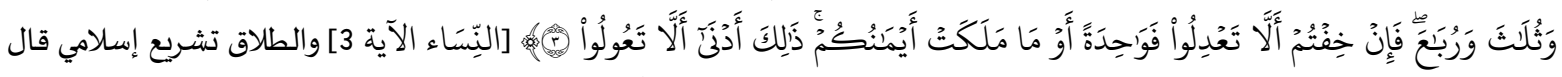

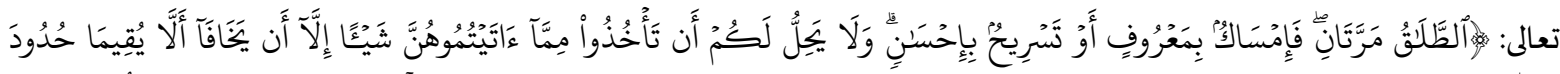

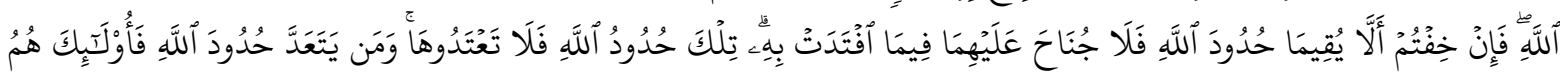

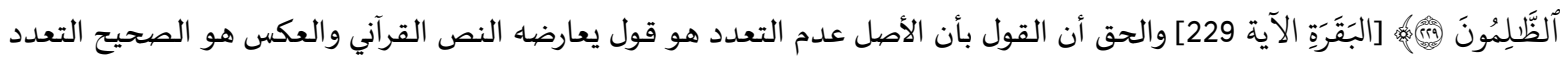

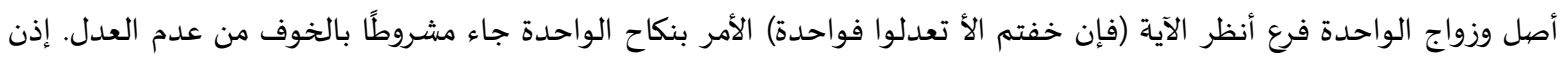

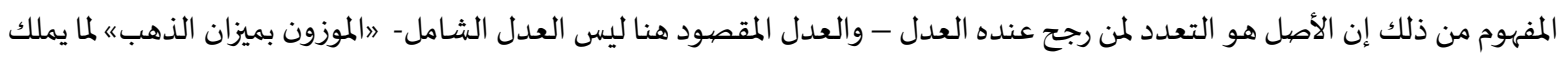

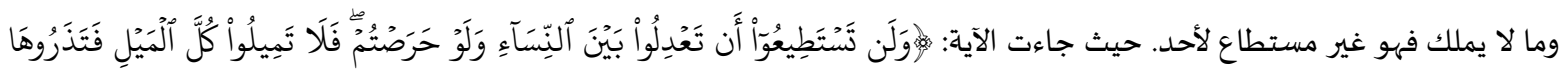

https://www.alfikra.org/chapter_view_a.php?book_id=23\&chapter_id=11 72 https://www.alfikra.org/chapter_view_a.php?book_id=23\&chapter_id $=11^{73}$ 14 الرسالة الثانية، مرجع سابق ص 127-128.

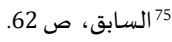
76 - السابق نفس الصفحة.

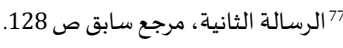

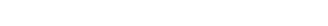




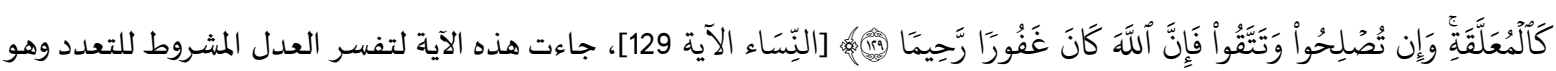

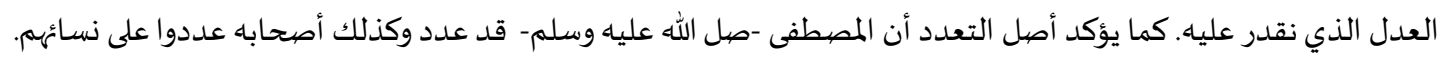

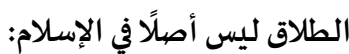

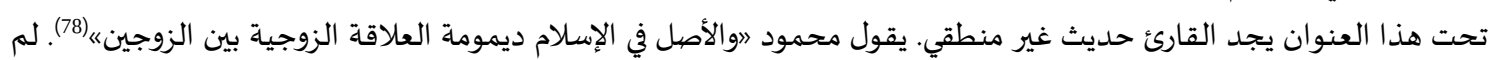

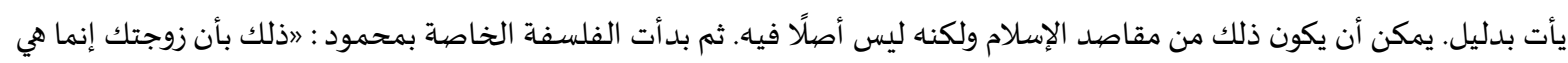

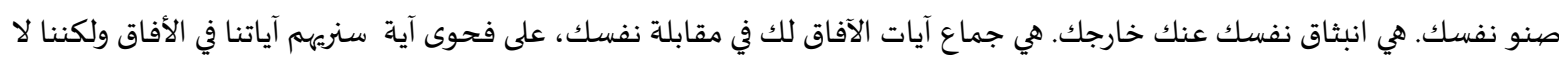

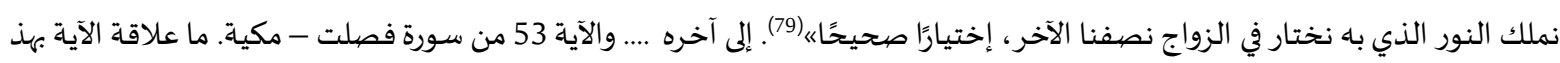

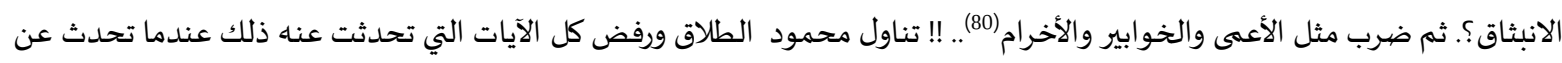

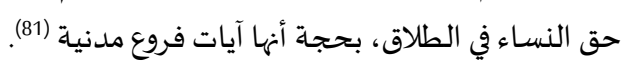

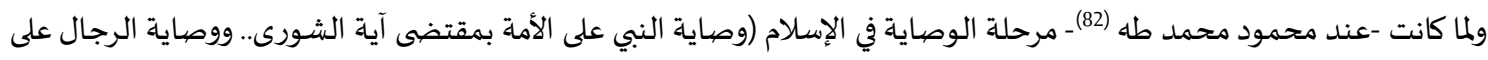

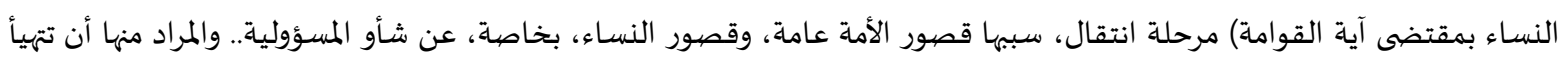

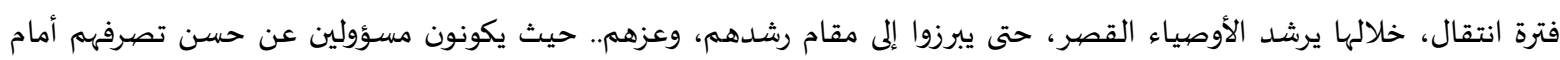

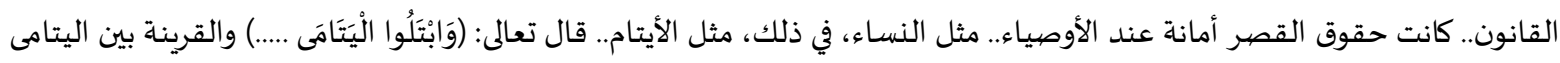

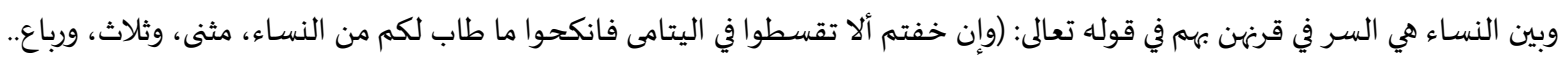

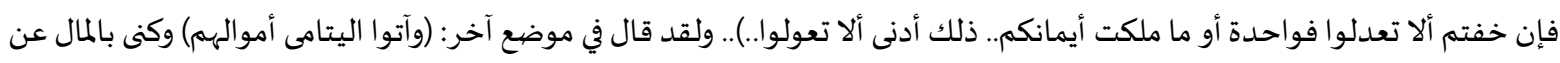

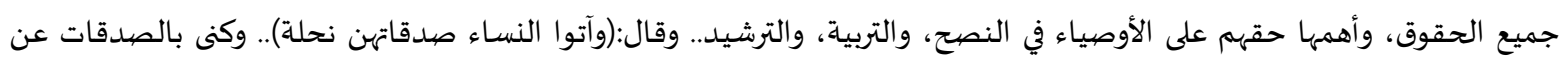

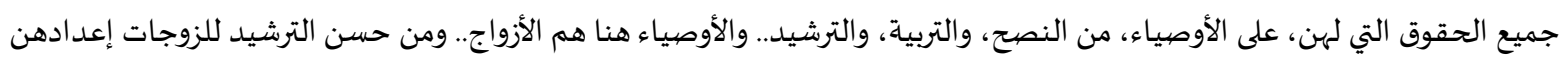

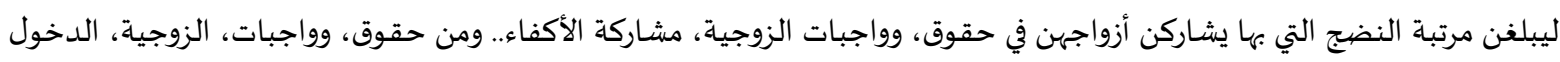

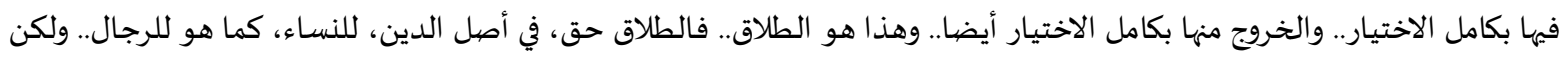

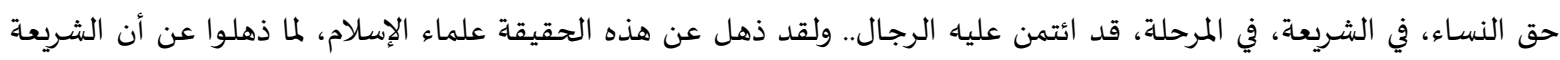

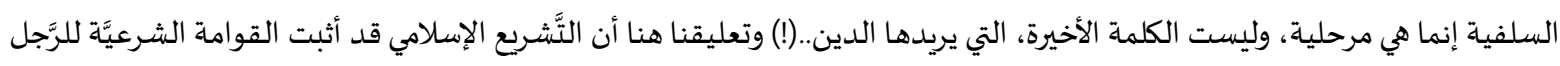

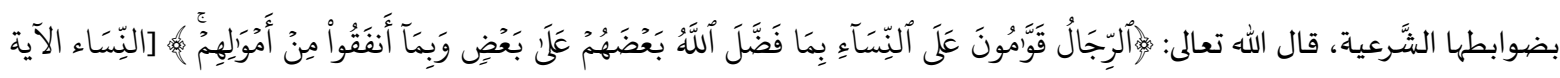

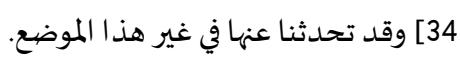

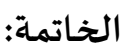

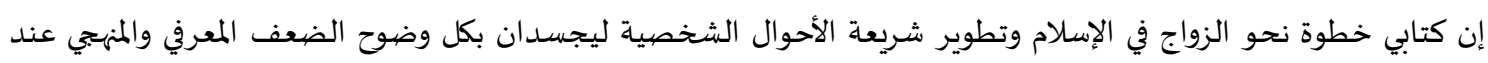

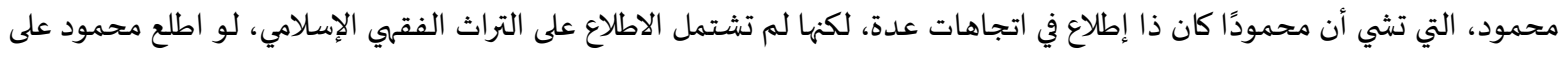

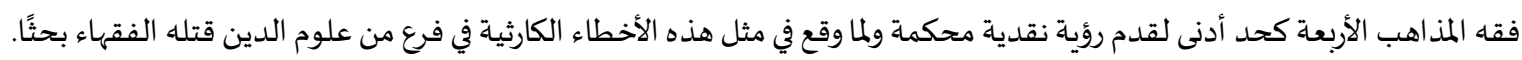
أولاً: النتائج:

وقد ظهرت لنا بوضوح هذه النتائج:

بنظرة لما طرحه محمود من تطوير لشريعة الأحوال الشخصية يتضح أنها تتلخص في الآتي:

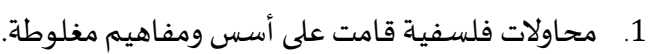

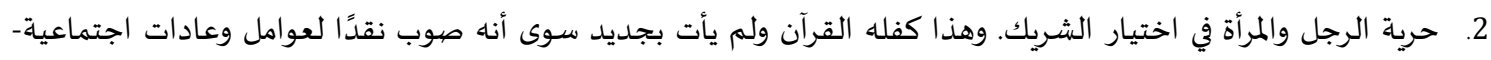

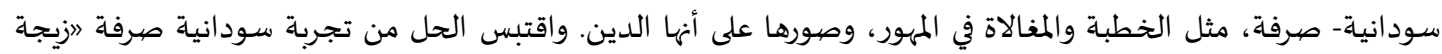

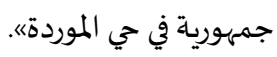
| (رفض مسألة الولي. * النفقة.* الطلاق.* تعدد الزوجات.

78 - الرسالة الثانية، مرجع سابق ص 129. السابق، ص 129 - 129 - 130. 80 81 https://www.alfikra.org/chapter_view_a.php?book_id=23\&chapter_id=11 82 
• التطوير عند محمود؛ وافق بعض الاختيارات الفقهية المعروفة منذ قرون، وصوب سهام نقده لبعض العادات الاجتماعية »السودانية على وجه الخصوصه التي توهم أنها من الدين، وقد منع الطلاق وتعدد الزوجات دون دليل أو قرينة.

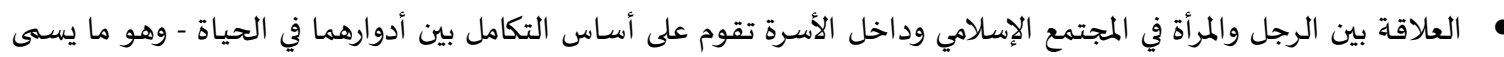

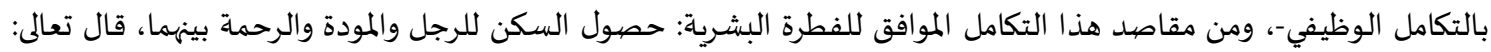

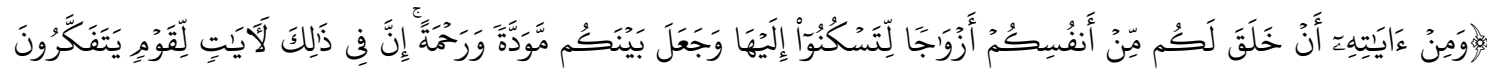

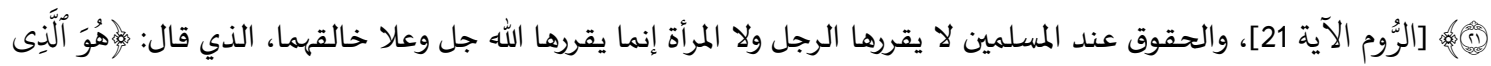

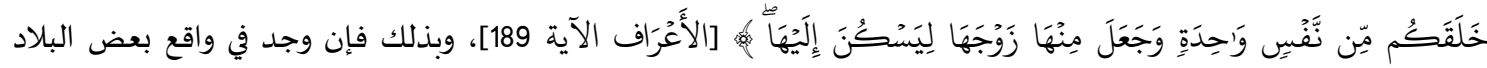
الإسلامية حيف في الحقوق وإهمال في أداء الواجبات من طرف تجاه آخر؛ فهو نتيجة لانحراف عن الدين، وجهل بأحكامه وضعف لِّف

إيمان بالله سبحانه وتعالى.

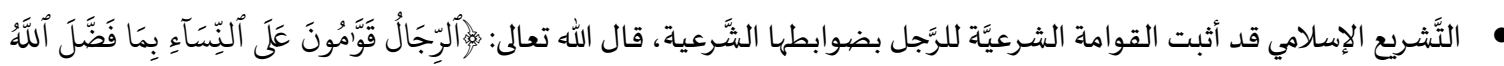

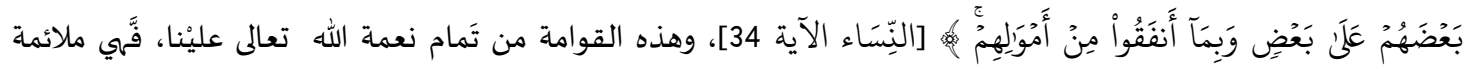

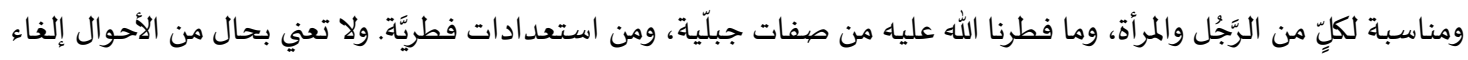

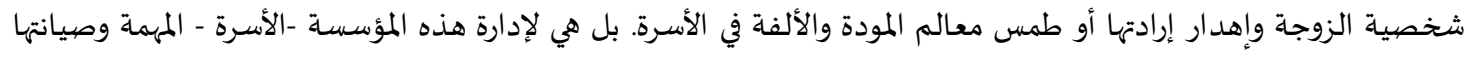
وحمايتها. من أعلى القيم التي رعتها الشريعة الإسلامية قيمة المحافظة على الحياة الأسرية والزوجية. وحديث القرآن الكريم عن المرأة يدور

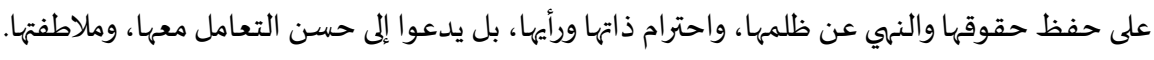

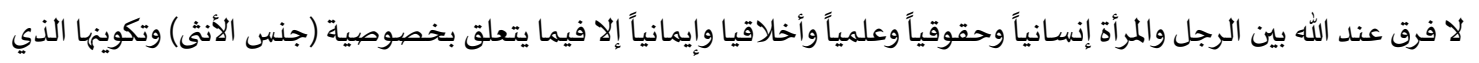
بدوناه لا يكتمل العالم. وافق محمود الأحناف فيما ذهبوا قبل مئات السنين. لويرى أبوحنيفة وأبو يوسف: أن المرأة العاقلة البالغة لها الحق في مباشرة

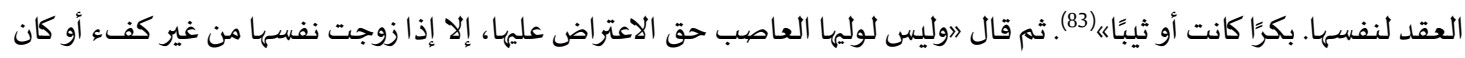
مهرها أقل من مهر المثل)(84). جعل محمود للزواج صيغتين أحداهما في الحقيقة والأخرى في الشريعة لهناك زواج في لالحقيقةشی.. وهناك زواج في 》الشريعة《..وهذا ليس له أصل في أصول الدين وبدعة ليس لها أس تقوم عليه. ونجد أن كل مابذله محمود من تعابير فلسفية حول الزواج في الحقيقة كان بعيدًا كل البعد عن المنهجية، وفياه مفاهيم مغلوطاهية. محمود محمد طه يختلف في المنهج الفكري عن كل المجددين الذين يرون إمكانية كفالة حقوق المرأة باجتهادات جديدة في

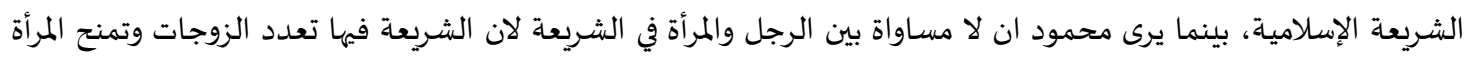

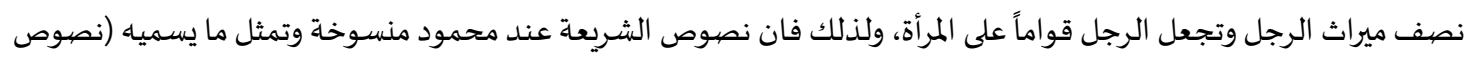
الفروع) التي كانت صالحة للتطبيق في ظروف القرن السابع الميلادي في مقابل (نصوص الأصول) الصالحة للتطبيق الآن. تشريع قوامة الرجل على المرأة في الإسلام ليس أصلا وانما الأصل المساواة وتشريع تعدد الزوجات في الإسلام ليس أصلاً وانما الأصل الزوجة الواحدة للزوج الواحد. وتشريع الطلاق ليس أصلاً في الإسلام وإنما هو تشريع انتقال يسير مجتمعاً إسلامياً ناقصاً إلى مجتمع إسلامي ناضج يكون أختيار

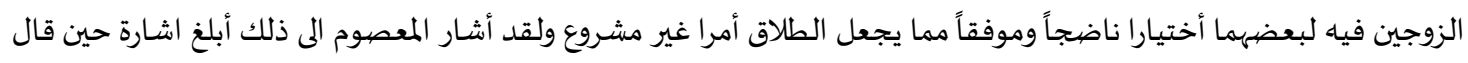

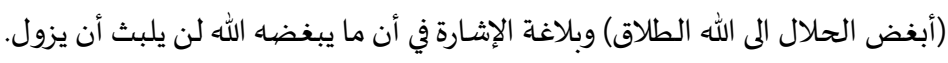
شريعة الأصول - حسب تسميته- تمنع التعدد، في معنى ما تطالب بالعدل.. والعدل يستحيل بين زوجتين.. دع عنك أربعا.. وإنما جاء تعدد الزوجات في شريعة الفروع، حيث كانت هي صاحبة الوقت، في القرن السابع.. ولم تكن حكمة التشريع، يومئذ، لتسمح بشريعة الأصول..! 
محمود محمد طه تناول الزواج في الحقيقة مقابل الزواج في الشريعة، وبنفس الطريقة جعل الزواج في شريعة الأصهول مقابل

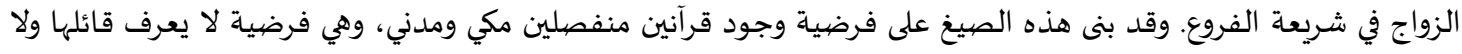

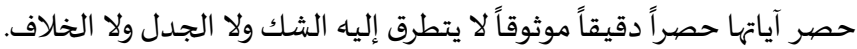
الكتاب ليست به منهجية واضحة ولا تطوير يحل مشكلات اليوم. لقد صهمم الكتاب ليمنع الطلاق وتعدد الزوجات، ويلغي المهر

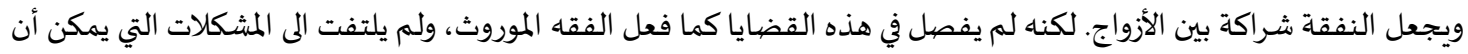
تنجم من أحكامه هذه.

المراجع:

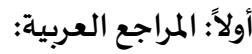

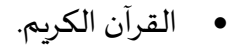

1.

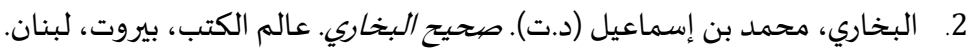

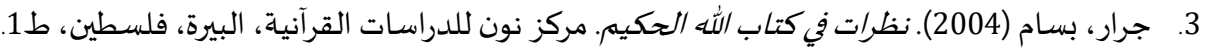

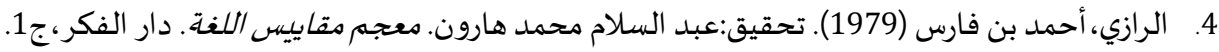

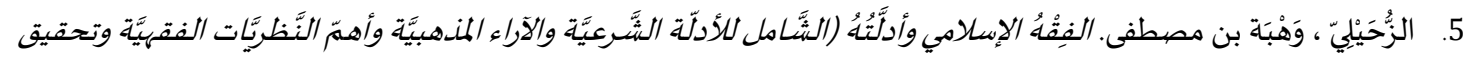

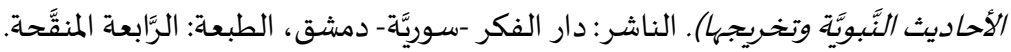

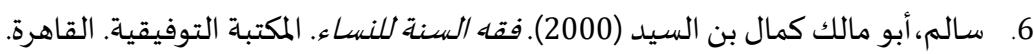
7.

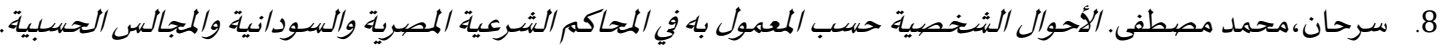

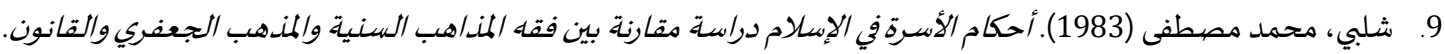
الطبعة الرابعة، الدار الجامعية للطباعة والنشر. 10. طه، محمود محمد طه (1981). من دقائق حقائق الدين. 11. طه، محمود محمد طه (1399ه). تطوير شريعة الأحوال الشخصية. الطبعة الثالثة.

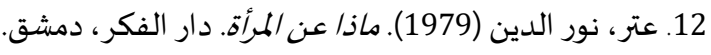

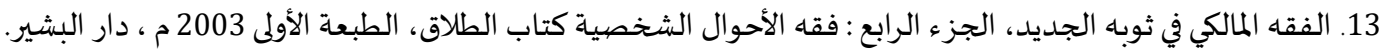

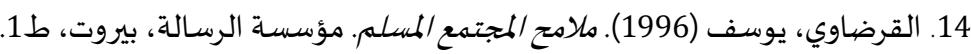

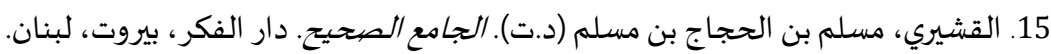

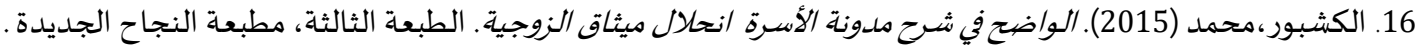
16. لمحات من حياة الأستاذ محمود محمد طه. إصدارات مركز الأستاذ محمود محمد طه الثقافئ.

ثانياً: المو اقع الإلكترونية: - م

1. https://www.alfikra.org/chapter_view_a.php?book_id=23\&chapter_id=1 
المجلة الدولية للدراسـات الإسلامية المتخصصية

International Journal of Specialized Islamic Studies (SIS)

www.refaad.com

Journal Homepage: https://www.refaad.com/views/SIS/Home.aspx

ISSN: 2617-6246(Online) 2617-6238(Print)

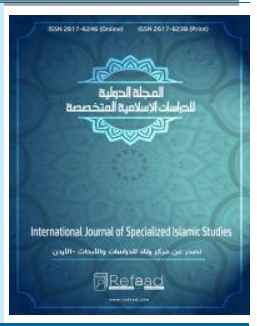

\title{
The methodology of Mahmoud Muhammad Taha in his tow books a step toward marriage in Islam and the development of personal status law
}

\author{
Ismail Siddig Osman \\ Associate Professor, College of Humanities, Department of Comparative Religion, University of Bahri, \\ Sudan \\ dr.ismailsiddig@gmail.com
}

\author{
Abd Elillah Kunna \\ University of Bahri, College of Humanities, Department of Comparative Religion, University of Bahri, \\ Sudan \\ kunasugud@gmail.com
}

Received: 25/9/2021 Revised: 27/10/2021 Accepted: 24/11/2021 DOI: https://doi.org/10.31559/SIS2021.6.3.2

Abstract: In this study which is named (methodology of Mahmoud Muhammad Taha in his two books "Step towards Marriage in Islam and "Development of Personal Status Law"), the researchers focused on one of the most important books written by Mahmoud i.e. "Development of Personal Status Law", beside other so essential two books written by him which are "The Second Massage of Islam" and "The Massage of Pray". In this study, the researchers tried to explore the main sources of Mahmoud ideas. They looked into the similarities and differences between his ideas and those of other Islamic intellectuals and reformers and what was written in former Islamic scholar's books. All Islamic scholars believe that all women's rights can be maintained, preserved and granted by the shari'a laws. Whereas Mahmoud believes that shari'a laws cannot do that because women and men are not equal within the shari'a laws. Mahmoud believes that shari'a laws allow Polygamy which made women to have half of the inheritance than men by shari'a laws and adopt "Qawwama" i.e. the support of men towards women. On contrary to all Islamic scholars' beliefs, Mahmoud believes that these issues are not originally part of Islam. He also believes that women and men should be absolutely equal. Based on his beliefs, he prohibited Polygamy and rejected all laws concerning divorce.

The researchers concluded that what is meant by "Development of Personal Status Law" is not actually making any sort of development in Personal Status Law, nor having any solution for various types of problems that can emerge during daily life between married couples. They concluded that this book is designed specially to prohibit Polygamy and to reject all laws concerning divorce. In addition, it cancelled the dower; also it obligates couples to share spendable equally. On the other hand, this book ignored all issues of inheritance although they are essential parts of Personal Status Law. The researchers adopted the analytical survey method.

Keywords: Mahmoud Muhammad Taha; Development of Personal Status Law; women's rights.

\section{References:}

1. ' 'tr, Nwr Aldyn (1979). Mada 'n Almrah. Dar Alfkr, Dmshq.

2. Albkhary, Mhmd Bn Esma'yl (D.T). Shyh Albkhary. 'alm Alktb, Byrwt, Lbnan.

3. Alefryqy, Mhmd Bn Mkrm (1990). Lsan Al'rb. Dar Sadr, Byrwt.

4. Alfqh Almalky Fy Thwbh Aljdyd, Aljz' Alrab': Fqh Alahwal Alshkhsyh Ktab Altlaq, Altb'h Alawla 2003 M, Dar Albshyr.

5. Jrar, Bsam (2004). Nzrat Fy Ktab Allh Alhkym. Mrkz Nwn Lldrasat Alqranyh, Albyrh, Flstyn, T1.

6. Alkshbwr, Mhmd (2015). Alwadh Fy Shrh Mdwnh Alasrh Anhlal Mythaq Alzwjyh. Altb'h Althalthh, Mtb't Alnjah Aljdydh. 
7. Lmhat Mn Hyah Alastad Mhmwd Mhmd Th. Esdarat Mrkz Alastad Mhmwd Mhmd Th Althqafy.

8. Alqrdawy, Ywsf (1996). Mlamh Almjtm' Almslm. M'sst Alrsalh, Byrwt, T1.

9. Alqshyry, Mslm Bn Alhjaj Bn Mslm (D.T). Aljam' Alshyh. Dar Alfkr, Byrwt, Lbnan.

10. Alrazy, Ahmd Bn Fars (1979) Thqyq:'bd Alslam Mhmd Harwn. M'jm Mqayys Allghh. Dar Alfkr, J1.

11. Salm, Abw Malk Kmal Bn Alsyd (2000). Fqh Alsnh Llnsa'. Almktbh Altwfyqyh. Alqahrh.

12. Alsba'y, Mstfa (1961). Almrah Byn Alfqh Walqanwn. M'sst Alrsalh, Byrwt, T3.

13. Shlby, Mhmd Mstfa (1983). Ahkam Alasrh Fy Aleslam Drash Mqarnh Byn Fqh Almdahb Alsnyh Walmdhb Alj'fry Walqanwn. Altb'h Alrab'h, Aldar Aljam'yh Lltba'h Walnshr.

14. Srhan, Mhmd Mstfa. Alahwal Alshkhsyh Hsb Alm'mwl Bh Fy Almhakm Alshr'yh Almsryh Walswdanyh Walmjals Alhsbyh.

15. Th, Mhmwd Mhmd Th (1981). Mn Dqa'q Hqa'q Aldyn.

16. Th, Mhmwd Mhmd Th (1399h). Ttwyr Shry'h Alahwal Alshkhsyh. Altb'h Althalthh.

17. Alzuhýly, Whbh Bn Mstfa. Alfqhu Aleslamy Wadltuhu (Alsháml Lladlh Alshŕ'yh Walara' Almdhbyh Wahm Alnzryát Alfqhyh Wthqyq Alahadyth Alnbwyh Wtkhryjha). Alnashr: Dar Alfkr -Swryh- Dmshq, Altb'h: Alráb'h Almnqhh. 